\title{
Joint development normal to regional compression during flexural-flow folding: the Lilstock buttress anticline, Somerset, England
}

\author{
Terry Engelder ${ }^{\mathrm{a}, *}$, David C.P. Peacock ${ }^{\mathrm{b}}$ \\ ${ }^{\mathrm{a}}$ The Department of Geosciences, The Pennsylvania State University, University Park, PA 16802, USA \\ ${ }^{\mathrm{b}}$ Department of Geology, SUNY at Buffalo, Buffalo, NY 14260, USA
}

Received 4 February 2000; accepted 20 June 2000

\begin{abstract}
Alpine inversion in the Bristol Channel Basin includes reverse-reactivated normal faults with hanging wall buttress anticlines. At Lilstock Beach, joint sets in Lower Jurassic limestone beds cluster about the trend of the hinge of the Lilstock buttress anticline. In horizontal and gently north-dipping beds, $J_{3}$ joints ( $295-285^{\circ}$ strike) are rare, while other joint sets indicate an anticlockwise sequence of development. In the steeper south-dipping beds, $J_{3}$ joints are the most frequent in the vicinity of the reverse-reactivated normal fault responsible for the anticline. The $J_{3}$ joints strike parallel to the fold hinge, and their poles tilt to the south when bedding is restored to horizontal. This southward tilt aims at the direction of $\sigma_{1}$ for Alpine inversion.

Finite-element analysis is used to explain the southward tilt of $J_{3}$ joints that propagate under a local $\sigma_{3}$ in the direction of $\sigma_{1}$ for Alpine inversion. Tilted principal stresses are characteristic of limestone-shale sequences that are sheared during parallel (flexural-flow) folding. Shear tractions on the dipping beds generate a tensile stress in the stiffer limestone beds even when remote principal stresses are compressive. This situation favors the paradoxical opening of joints in the direction of the regional maximum horizontal stress. We conclude that $J_{3}$ joints propagated during the Alpine compression caused the growth of the Lilstock buttress anticline. (C) 2001 Published by Elsevier Science Ltd.
\end{abstract}

\section{Introduction}

An old paradigm is that outer-arc stretching leads to foldrelated jointing (Van Hise, 1896). Outer-arc stretching is associated with tangential longitudinal strain folds that develop when a homogeneous, isotropic layer is buckled (Price and Cosgrove, 1990). The tangential longitudinal strain fold is divided by a neutral surface beyond which the inner arc of the fold is compressed. Joints that initiate in the outer arc of anticlines propagate down to but do not cross the neutral surface. When fold-related jointing penetrates the entire thickness of a bed, the tangential longitudinal strain model is less useful as a mechanism to explain the strain that may have caused jointing. This is also true when jointing is well developed in the limbs of folds or at inflection points where strain goes to zero in a tangential longitudinal strain fold. To understand the development of jointing in the limbs of folds, we must look to another model. Flexural flow folds have maximum strains at the inflection points and zero strain at the hinges (Price and Cosgrove, 1990).

\footnotetext{
* Corresponding author.

E-mail address: engelder@geosc.psu.edu (T. Engelder).
}

We consider the possibility that one or more sets of unfilled joints of the Bristol Channel were contemporaneous with flexural-flow folding during Alpine shortening. Here, we describe field data gathered to test this hypothesis. We presume that the joint geometries interpreted to date from the Alpine inversion reflect the superposition of local and remote (i.e. regional) stress conditions. We also use the orientation of systematic joints in carbonate beds to constrain a mechanical model for stress distribution during flexural-flow folding in interlayered limestone-shale beds. With the help of this mechanical model, we propose a new mechanism for the joint driving stress. This mechanism does not rely on outer-arc extension commonly cited as the conventional fold-related jointing mechanism. Under this new mechanism, fold-related joints are driven completely through beds without arrest at a neutral surface.

\section{The geology of Lilstock Beach: overview and previous work}

\subsection{The regional picture}

The Bristol Channel Basin is an E-W striking Mesozoic 


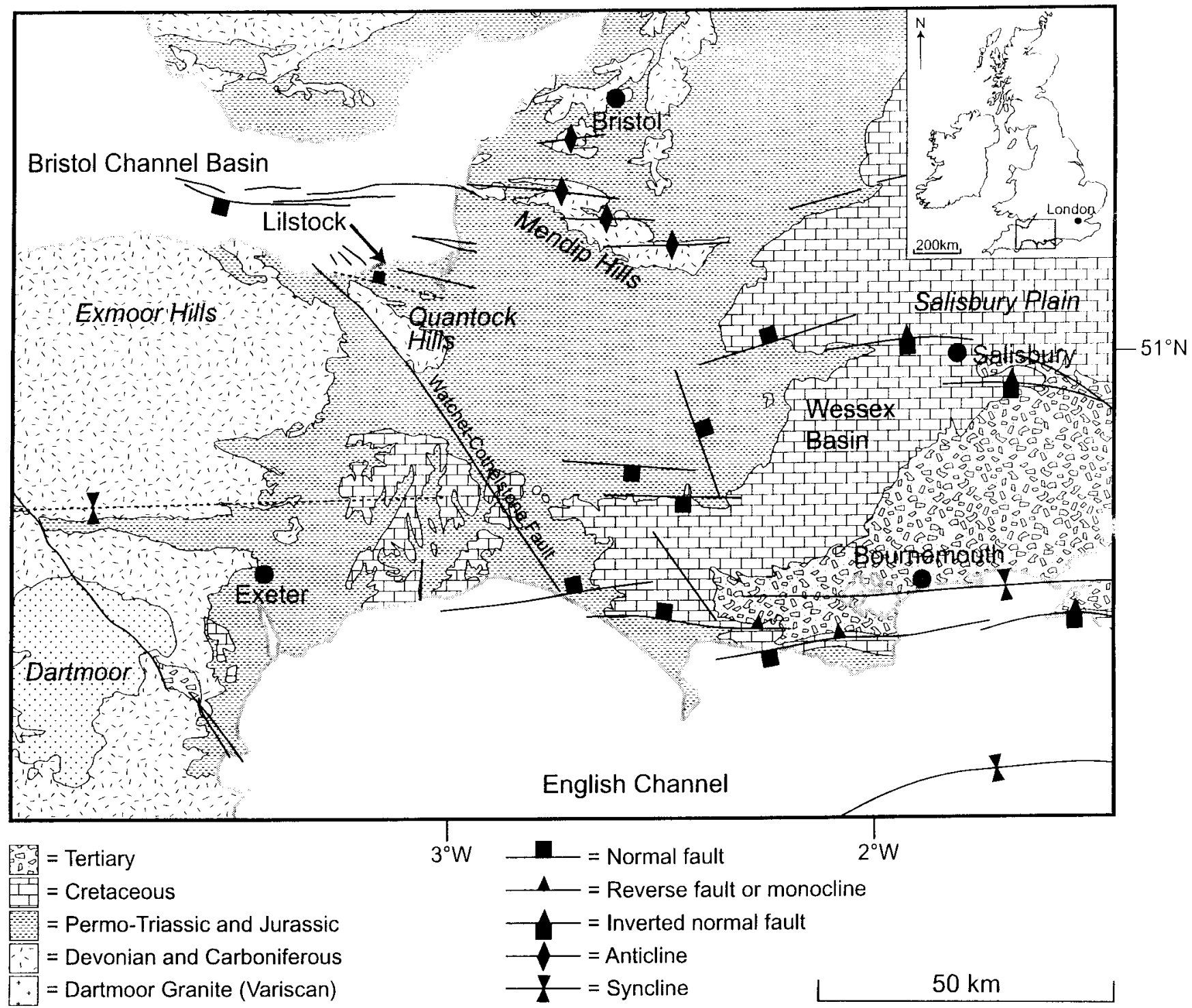

Fig. 1. Geological map of south-western Britain, showing the location of the Bristol Channel basin and Lilstock.

rift basin (Fig. 1). Normal faults dip either north or south to divide the basin into fault blocks (Dart et al., 1995). The basin was inverted in the Eocene and Oligocene during a period of $\mathrm{N}-\mathrm{S}$ compression associated with Alpine tectonics (Holloway and Chadwick, 1986; Arthur, 1989; Dart et al., 1995; Nemcok et al., 1995). Alpine deformation was accommodated by reverse-reactivation of normal faults, new thrust faults, new strike-slip faults, and by hanging wall buttress anticlines. Beck et al. (1993) define the "buttress effect" as resistance to displacement arising from a space problem; a body of rock can move only if it has somewhere to go. Buttress folds of Eocene to Oligocene age show a parallel geometry that is produced by flexural-flow with bed-parallel slip (Nemcok et al., 1995). Reverse faulting was more prevalent along the southern margin of the Bristol Channel Basin than on the north margin (Nemcok et al., 1995).
Three minor tectonic events post-date inversion, leaving one or more joint sets in the Jurassic rocks of the Bristol Channel and elsewhere in southern Britain.

1. A second Alpine event was characterized by NW-SE compression during the Miocene (e.g. Bergerat, 1987). Rawnsley et al. (1998) argue that the first joint set of the Bristol Channel area propagated in a stress field consistent with this Late Oligocene to Miocene Alpine compression.

2. Joints follow a propagation sequence consistent with an anticlockwise rotation of the regional maximum horizontal stress $\left(S_{\mathrm{H}}\right)$ from NW-SE to NE-SW through an $\mathrm{E}-\mathrm{W}$ orientation (Loosveld and Franssen, 1992). Joint sets in the Cotswold Hills to the north and east of the Bristol Channel also indicate a period of $\mathrm{E}-\mathrm{W}$ compression (Hancock, 1969). Rawnsley et al. (1998) suggest that later phases of unfilled jointing are a consequence of a progressive, basin-wide relaxation of the Alpine compression 

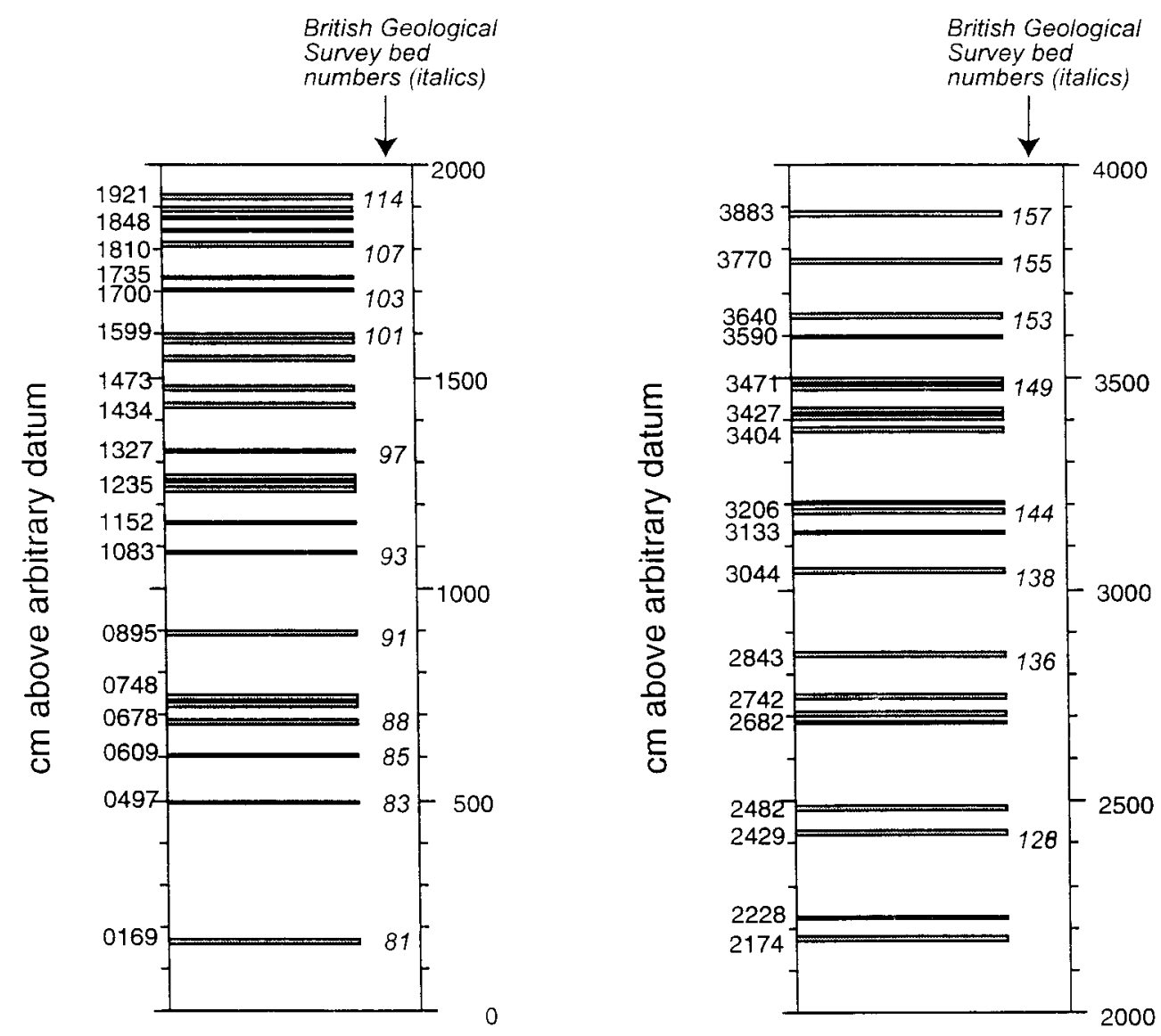

Fig. 2. Stratigraphic section at Lilstock Beach showing the position of 46 carbonate beds above an arbitrary datum. The beds are labeled according to their position relative to the datum. The British Geological Survey (Whittaker and Green, 1983) designation for each bed is also given.

in Late- to post-Miocene time. This interpretation is largely based on the observation that joints abut the faults rather than being displaced by them.

3. The lithospheric stress field in the NW European platform is presently in the same orientation as the Alpine stress field of the Miocene (Brereton and Evans, 1987; Zoback, 1992). Furthermore, the youngest joint set recorded throughout southern England correlates with the contemporary tectonic stress field (Bevan and Hancock, 1986; Hancock and Engelder, 1989). Hancock and Engelder (1989) argue that exhumation in a late-stage 'Alpine' stress field was responsible for these youngest NW-striking joints in northwestern Europe.

Evidence suggests, therefore, that a post-Miocene tectonic event caused a clockwise rotation of the European stress field, only to have it return to its 'Alpine' orientation, as required by the latest phase in jointing in northwestern Europe.

\subsection{Stratigraphic section}

The Blue Lias Formation of Lilstock Beach has more than 50 limestone beds between 5 and $40 \mathrm{~cm}$ thick (Whittaker and Green, 1983). Interlayered shales range from a few centimeters to $>300 \mathrm{~cm}$ thick. The layering of carbonate beds with intervening shales follows a distinct pattern that allows correlation of carbonate beds among and between fault blocks. We studied joint development in 25 of 46 carbonate beds in a 40-m thick section (Fig. 2). For ease of indicating vertical position in the section, we label beds using units of centimeters above an arbitrary datum. For example, bed 1848, $18.48 \mathrm{~m}$ above the datum, is featured prominently in the analyses of Loosveld and Franssen (1992) and Rawnsley et al. (1998). These beds also correspond to those Liassic beds identified in the British Geological Survey stratigraphic column (Whittaker and Green, 1983), as shown in Fig. 2.

\subsection{Faults and folds}

The structures on Lilstock Beach include a set of four north-dipping, high-angle faults that are offset by later strike-slip faults (Fig. 3). We divide Lilstock Beach using three of these high angle faults (faults 3, 4, and 5 of Rawnsley et al., 1998) and two strike-slip faults. The area north of fault 5 is called block 5 or "the bench" in recognition of Loosveld and Franssen (1992) mapping there. The other three blocks are hanging walls to faults 4, 3 and 1, and will be so labeled. We shall refer to the eastern, central, and western portion of each 'normal' fault block depending on 


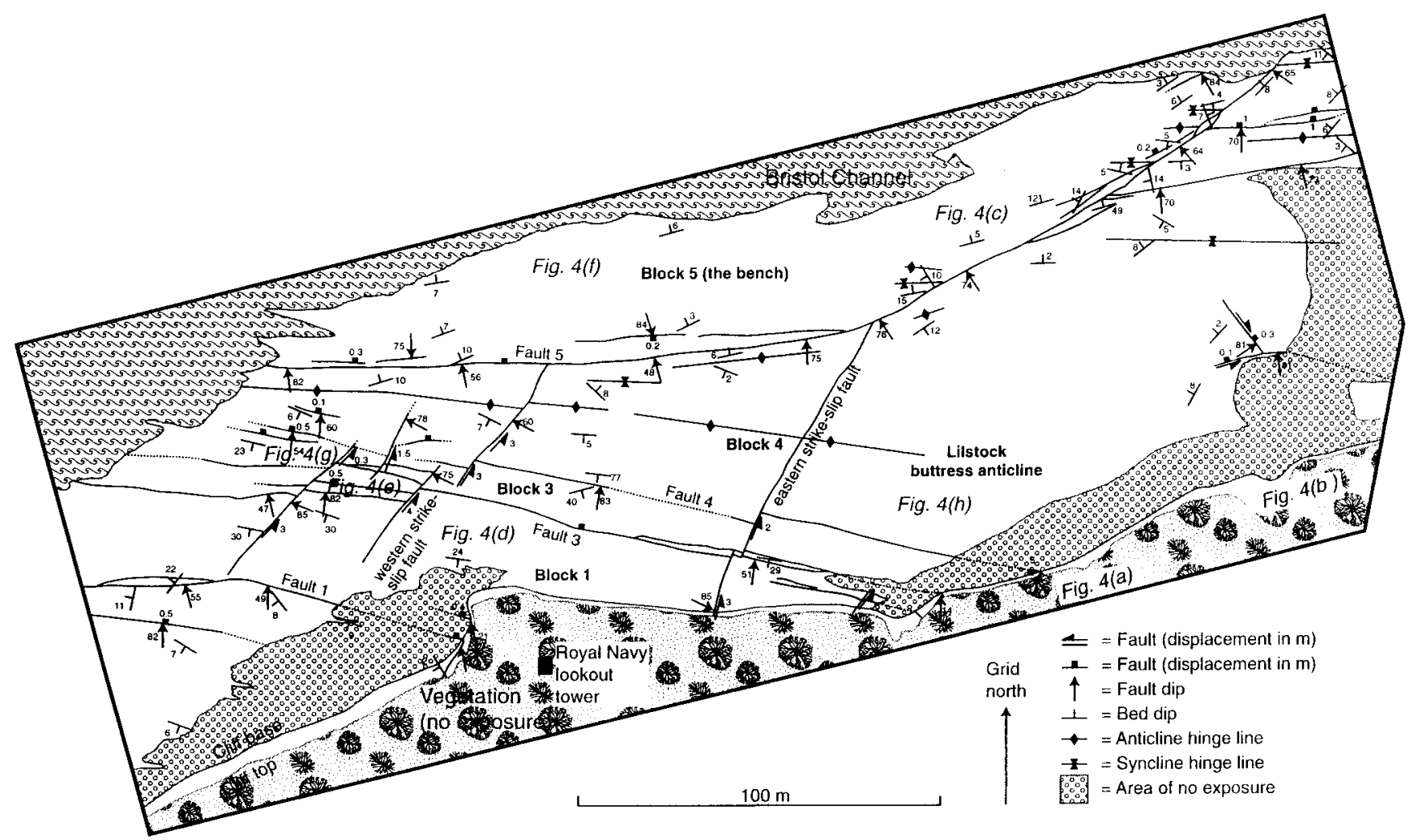

Fig. 3. Geological map of Lilstock Beach, Somerset (see location in Fig. 1) (adapted from Rawnsley et al., 1998). The locations of photos in Fig. 4 are indicated.

outcrop position relative to two prominent strike-slip faults (Fig. 3).

Separation at any point on the faults can be measured with confidence using the juxtaposition of bedding. Throw on at least one of the high angle faults (fault 4) was reversed during Alpine inversion. Reverse-slip may have occurred on the other faults, but the total throw was not reversed. The steep dip of fault 4 and its parallelism with normal faults in the area indicate that it originated as a normal fault. The inversion is inferred to be Alpine age, which is the age suggested for all of the other reverse faults in the region (e.g. Whittaker and Green, 1983; Dart et al., 1995). Net throw (the combination of normal slip and Alpine reverseslip) on the four faults with throw $>2 \mathrm{~m}$ is: fault $1 \approx 18.7 \mathrm{~m}$ (normal), fault $2 \approx 8 \mathrm{~m}$ (normal), fault $4 \approx 8 \mathrm{~m}$ (reverse), and fault $5 \approx 14 \mathrm{~m}$ (normal). The outcrop is also cut by numerous high-angle faults with $<2 \mathrm{~m}$ throw, which mostly exhibit normal-slip and are parallel to the strike of bedding. Strikeslip faults displace the high angle faults and the limbs of the Lilstock buttress anticline. The strike-slip faults are cutoff at fault 4 (Fig. 3), indicating that strike-slip faulting and some high angle faulting may have been contemporaneous (Kelly et al., 1998).

Block 4 consists of a large buttress fold, the Lilstock buttress anticline, with a gently dipping north limb and relatively steep south-dipping beds (Fig. $4 \mathrm{a}, \mathrm{b}$ ). The Lilstock buttress anticline originated as a reverse-drag fold
(Hamblin, 1965) during the Mesozoic normal faulting and was tightened during reverse-slip on fault 4 . Joints in the south-dipping limb of this anticline are the main focus of our study. Beds in the northern half of block 4 dip gently to the north $\left(<5^{\circ}\right)$, whereas beds in the southern half of the outcrop dip to the south and in places the dip is more than $30^{\circ}$. Along the south side of the Bristol Channel, dips of more than about $30^{\circ}$ are restricted to the flanks of buttress anticlines. For diagrams of the tight folding typical of buttress folds in the Mesozoic sedimentary rocks of the Somerset coast, see Peacock and Sanderson (1992; fig 7a) and Dart et al. (1995).

\subsection{Joints}

Joint development in the Jurassic Blue Lias Formation at Lilstock Beach rivals other well documented examples of multiple phases of jointing such as those found at Arches National Park, USA (Dyer, 1988; Cruikshank and Aydin, 1995) and on the Appalachian Plateau, USA (Nickelsen and Hough, 1967; Engelder and Geiser, 1980; Zhao and Jacobi, 1997; Younes and Engelder, 1999). Greater structural complexity, however, distinguishes the Bristol Channel outcrops from those of either Arches National Park or the Appalachian Plateau.

At Lilstock Beach, joints that originate within limestone beds are generally contained within these beds. With few 

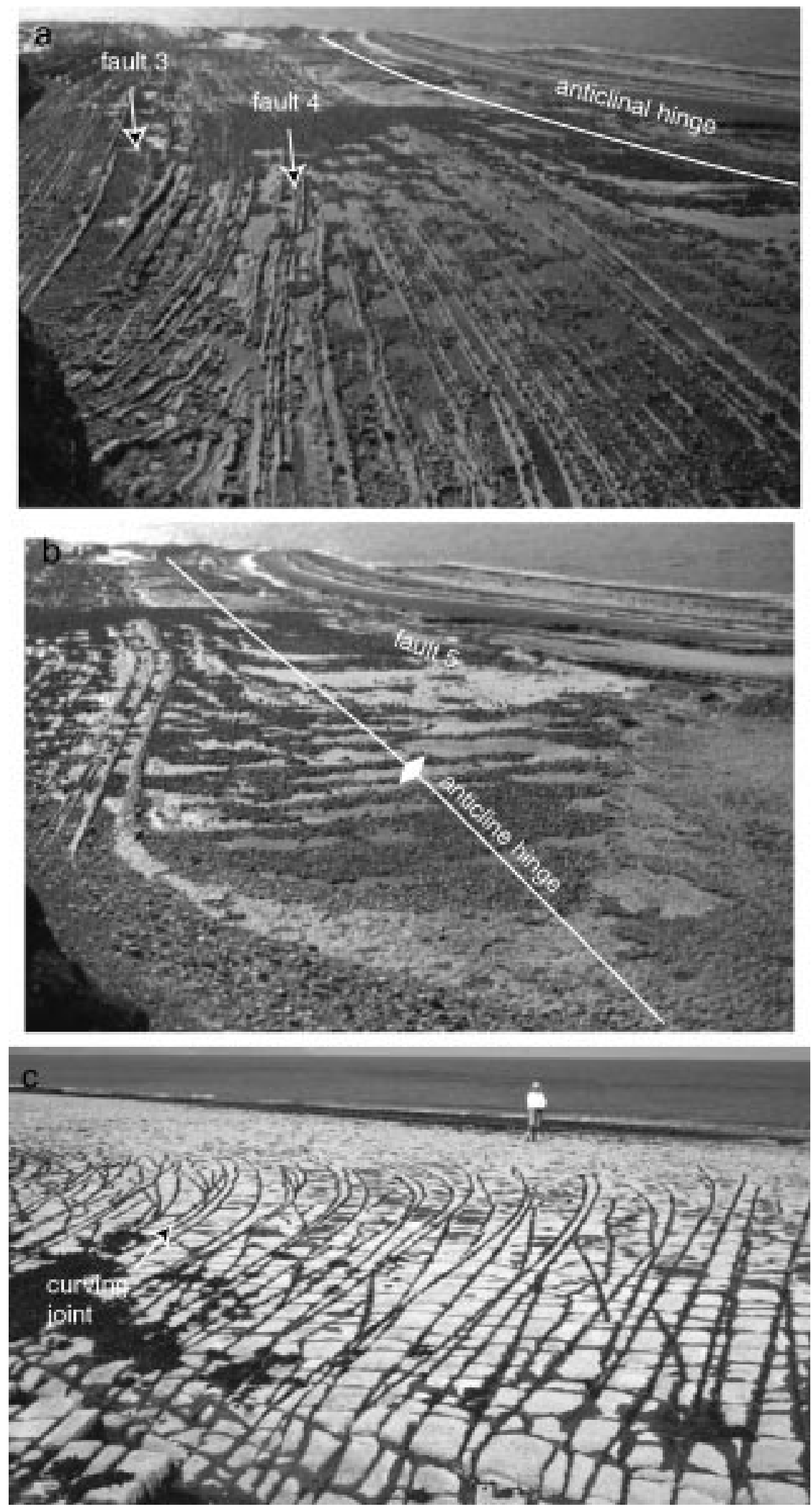

Fig. 4. (a) View looking NNW from the eastern cliff along faults 3 and 4 with the hinge of the buttress anticline shown in the background. (b) View looking NNW from the eastern cliff along the hinge of the Lilstock buttress anticline. Bed 0497 is visible in the foreground. A control sample from bed 0497 was taken across the hinge of the anticline and Fig. $4 \mathrm{~h}$ was taken at the point where bed 0497 rolls over into the limb of the anticline. (c) Curving joints in bed 1848 of fault block five. Photographer is standing on fault 5 (location shown in Fig. 3). (d) $J_{2}$ joints cutting two normal faults within bed 2429 of fault block 1 . (e) $J_{3}$ joints abutting a small (throw $<1 \mathrm{~m}$ ) normal fault in bed 1921 in the western portion of fault block three. A sinistral strike-slip fault offsets bed 1921 in the foreground by $2 \mathrm{~m}$. That fault is internal to the western portion of fault block 3. (f) Joint set development within bed 1848 on the bench north of fault 5 (see Figs. 2 and 3). Joint set $J_{2}$ is parallel to the direction of view. Sets $J_{4}$ and $J_{6}$ are oriented anticlockwise from set $J_{2}$, with $J_{6}$ anticlockwise from $J_{4}$. The view is looking south-east toward the cliff from where the photographs for Fig. 4(a,b) were taken. View across the bottom of the photograph is about $3 \mathrm{~m}$. (g) $J_{3}$ joints cutting veins and transecting beds dipping in a relay ramp developed during early extension in the western portion of fault block 3 (coin diameter $=27 \mathrm{~mm}$ ). (h) The anticlockwise relationship between $J_{2}$ and $J_{3}$ in bed 0497 where it rolls over into the south limb of the anticline. 

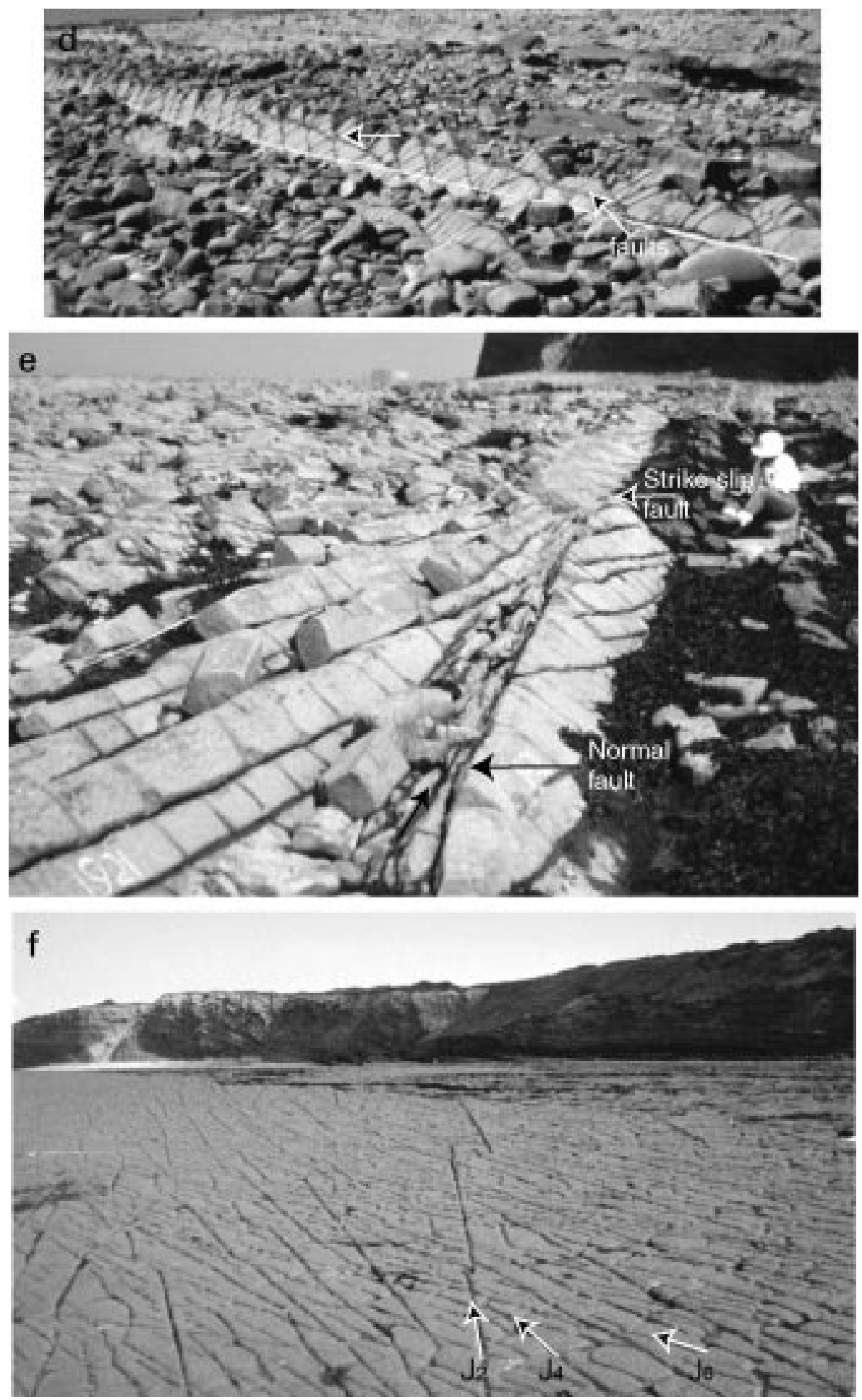

Fig. 4. (continued)

exceptions, shales are less well jointed and only rarely does a joint extend through a bedding contact from a limestone bed into a shale bed. The pattern of systematic jointing differs from one limestone bed to the next. This latter characteristic is responsible for the differences among earlier studies in terms of identifying and labelling the different joint sets at Lilstock Beach.
Prior to our study, joint sets in the limestone beds at Lilstock Beach were defined by Loosveld and Franssen (1992) and Rawnsley et al. (1998). Neither study was detailed enough to identify the full suite of joints that we discovered. Loosveld and Franssen (1992) focused on just one bed (i.e., 1848). In brief, based on regional evidence (Rawnsley et al., 1998) group joints at Lilstock into five 

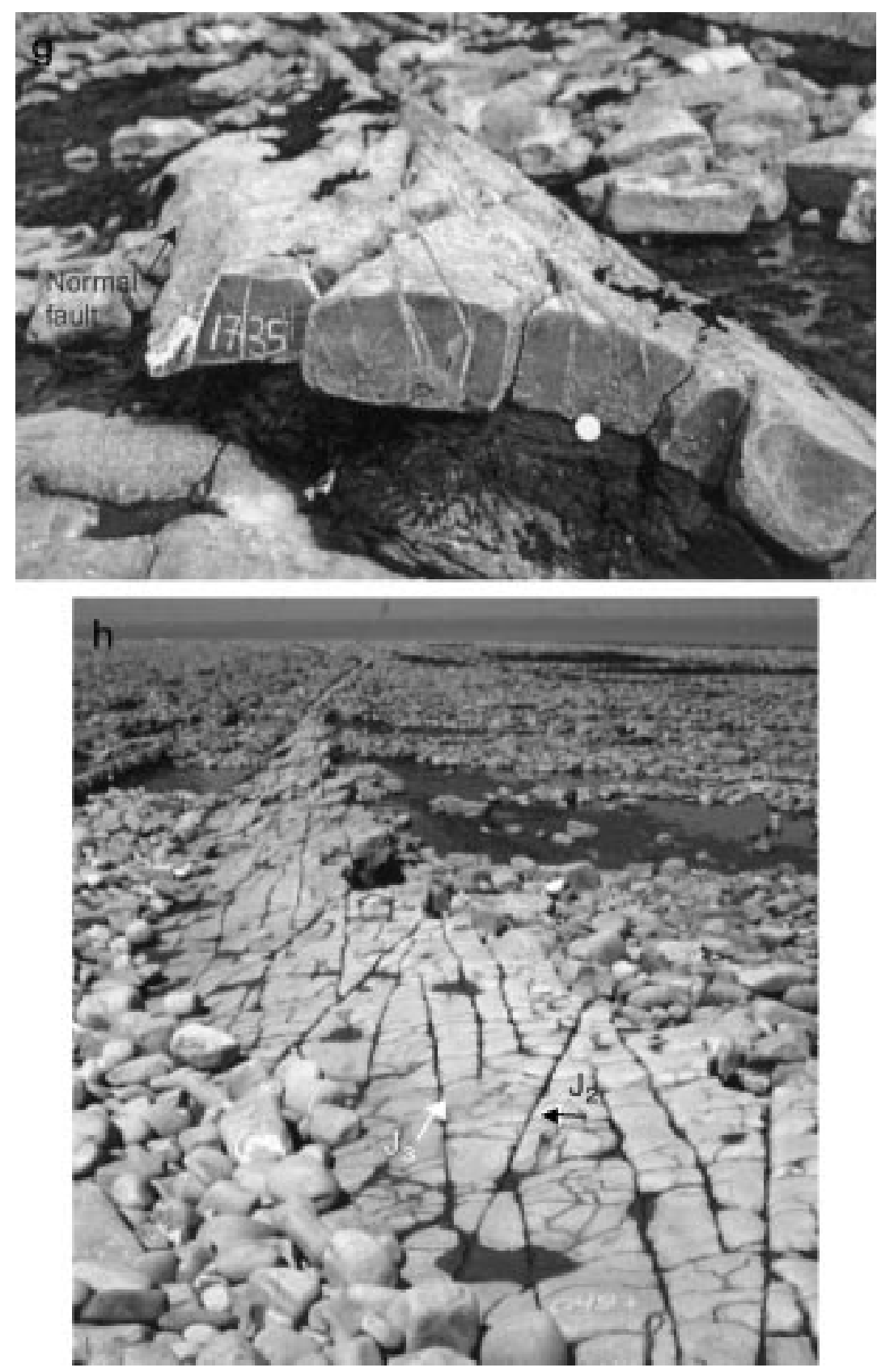

Fig. 4. (continued)

phases of development, starting with phase 1 joints striking $340^{\circ}$ and related to a regional Alpine compression. A subsequent anticlockwise reorientation of $S_{\mathrm{H}}$ is manifest by several joint sets at Lilstock Beach that are grouped as phase 3 joints (striking from $315^{\circ}$ to $290^{\circ}$ ) by Rawnsley et al. (1998). These are set 1 and 2 joints of Loosveld and Franssen (1992). Phase 4 of Rawnsley et al. (1998) is the propagation of a set of cross-joints at Lilstock Beach corresponding to set 3 and 4 joints of Loosveld and Franssen (1992).

During or after faulting, the regional stress field at Lilstock was perturbed by the presence of irregularities or large asperities along fault surfaces (Rawnsley et al., 1992). These perturbations are interpreted to have caused coeval phase 2 joints to curve from the otherwise straight propagation paths and to concentrate at the irregularities (Fig. 4c). There is no corroborating evidence that these joints propagated during Mesozoic extension. The most plausible interpretation is that limestone-limestone contact across the fault generated a local stress field during or after the period of high-angle reverse faulting on reactivated normal faults. Regardless, joint propagation followed fault initiation but not necessarily total slip. Curved trajectories of phase 2 joints in proximity to phase 1 joints are interpreted to mean that phase 1 joints were open and also perturbed the stress field during stage 2 joint propagation (Dyer, 1988; Rawnsley et al., 1992, 1998). 
In summary, from qualitative evidence the timing of joint propagation at Lilstock is constrained by vein or fault development only to the extent that the joints postdate early normal faulting and vein development. Commonly, joints propagate after normal fault development, as indicated by abutting and cutting (e.g. Fig. 4d, e). Some joints radiate from concentration points on faults (e.g. Fig. 4c). As stress concentration points are a natural consequence of slip on an irregular fault, these curving joints could have propagated during a later stage of slip.

\section{Data collection}

Our field approach at Lilstock Beach was to sample systematic joints in a volume of the Blue Lias measuring $40 \mathrm{~m}$ thick by $200 \mathrm{~m}$ long $(\mathrm{E}-\mathrm{W})$. The repetition of the section by high angle faults permitted sampling up to 50 $\mathrm{m}$ in the third dimension (i.e. $\mathrm{N}-\mathrm{S}$ ) of some beds. In sampling the volume, we were particularly interested in the affect of Alpine inversion on joint development. Our premise is that if joints propagated during Alpine inversion, they are likely to be found in the south-dipping limb of the Lilstock buttress anticline in block 4. This premise is assumed because the relatively steep dip of these beds indicate they are the most strained rocks at Lilstock, so are most likely to develop fold-related joints. To test for this possibility, the joint patterns in subhorizontal surfaces in block 5 and the hinge area of the Lilstock buttress anticline in block 4 were measured to serve as a control sample.

The joint patterns in dipping and subhorizontal limestone beds were qualitatively compared. Standard scanline techniques were then used to record the location and orientation of each systematic joint (LaPointe and Hudson, 1985). We sampled some cross joints (i.e. the polygonal joints as mapped by Rawnsley et al., 1998) but did not methodically gather a complete data set largely because these joints are non-systematic and so numerous that they would have prohibitively slowed the sampling of systematic joint sets. We identified the joint sets in each bed based on abutting and orientation characteristics and correlated them from bed to bed during data reduction in the laboratory. The most subjective aspect of set assignment involved curving joints that qualified for membership in more than one set based on orientation.

\section{Joint sets in the Blue Lias}

\subsection{Identification of joint sets}

A joint set is a collection of systematic parallel joints (Hodgson, 1961). Poles to joints of a systematic set fall, however, in a cluster several degrees wide because individual joints are never perfectly planar and there are measurement errors (Fig. 5). Because of these variations, joint sets separated by $<10^{\circ}$ in orientation may have overlapping clusters of poles in a stereographic plot. In this case, placing an individual joint into one set or the other is impossible during post-fieldwork analysis alone. Hence, we rely on field notes, where joints were presorted into sets within a particular bed. The exercise of grouping joints into distinct sets was most difficult when several beds are involved and when joint sets curve as they do near the faults of Lilstock Beach. Our guide for grouping joints into sets in the southdipping limb was the control sample from the subhorizontal beds of fault block 5 and the axial area of the Lilstock buttress anticline in block 4 .

\subsection{Control sample: joint sets in subhorizontal beds of blocks 4 and 5}

To establish a control sample we ran scanlines on four subhorizontal beds. Each scanline was a minimum of $35 \mathrm{~m}$ in length but could be much longer depending on the quality of the outcrop. Loosveld and Franssen (1992) identify six joint sets in bed 1848 in fault block 5, away from the faults (Fig. 3). As a reference for identifying joint sets in further data analysis, we use a simplified AVTD plot (see Wise and McCrory, 1982) from bed 1848 (Fig. 4f and Fig. 6a). Here, the three sets with the longest joints in order of formation strike approximately $298^{\circ}, 284^{\circ}$, and $262^{\circ}$, respectively. They are sets 1, 2, and 3-4 of Loosveld and Franssen (1992). Another prominent joint set striking at approximately $321^{\circ}$ appears in bed 1921 of fault block 5. As a rule, joint development in one competent bed is independent of development in other competent beds.

A second flat, well-exposed surface consists of beds 0169 and 0497 near the sub-horizontal hinge of the Lilstock buttress anticline in block 4 (Fig. 3). Here, four joint sets strike approximately $291^{\circ}, 280^{\circ}, 269^{\circ}$, and $<260^{\circ}$ (Fig. 6b). The first is a joint set not present in bed 1848 of fault block 5. The second correlates with set 2 of Loosveld and Franssen (1992). The third may correlate with set 3 of Loosveld and Franssen (1992) but because it differs in strike by $7^{\circ}$, we identify another new set. Considering the sets from both control samples in combination, these six joint sets are named $J_{1}\left(330^{\circ}-310^{\circ}\right), J_{2}\left(310^{\circ}-295^{\circ}\right), J_{3}\left(295^{\circ}-285^{\circ}\right), J_{4}$ $\left(285^{\circ}-275^{\circ}\right), J_{5}\left(275^{\circ}-265^{\circ}\right)$, and $J_{6}\left(<265^{\circ}\right)$ (Fig. 6). Sets 5 and 6 of Loosveld and Franssen (1992) are not immediately apparent as joint sets in the south-dipping limb and, therefore, not included as part of our control sample.

\subsection{Joint frequency in subhorizontal beds}

Six joint sets appear on the subhorizontal bedding surfaces of fault blocks 4 and 5 (Fig. 6). While inspection of our simplified AVTD diagrams give qualitative sense of relative joint density, we normalize the data on joint occurrence to compare joint development in subhorizontal beds with beds that have been tilted by Alpine inversion. Our normalization technique is designed to give an indication of joint density in limestone beds throughout a volume 

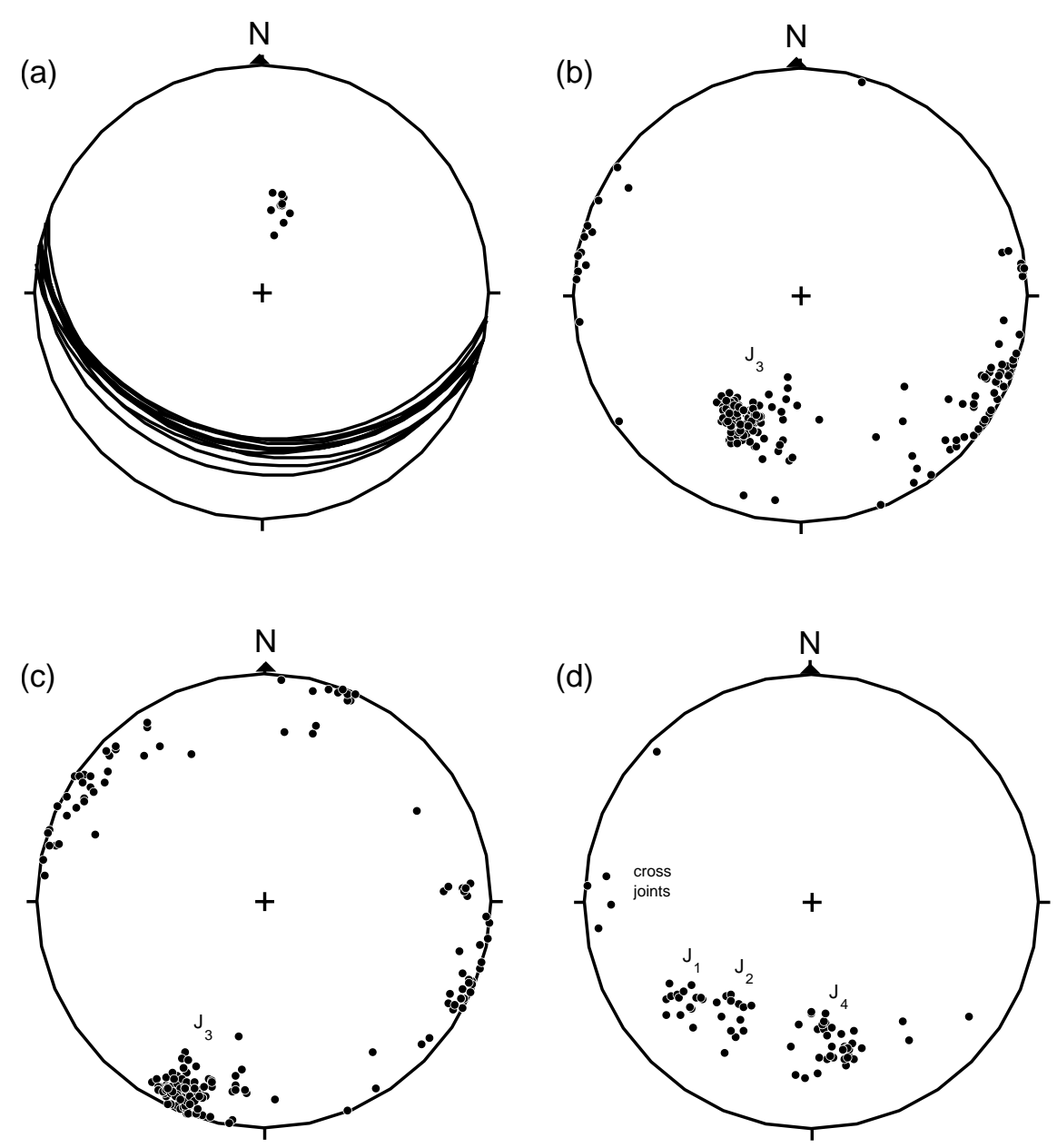

Fig. 5. Lower hemisphere stereographic projections for beds and joints in fault block 1. (a) Bedding traces and poles for bed 2429. (b) Present-day poles to joints in bed 2429. (c) Poles to joints in bed 2429 with bed dip removed. (d) Present-day poles to joints in bed 3883.

where the joint pattern differs among the various beds. The normalization accounts for bedding orientation, joint orientation, scanline orientation, scanline length, and bed thickness.

Steps for normalization include the following. First, all poles to joints were transformed, with bedding rotated to the horizontal around a local horizontal fold axis. Second, the orientation sampling bias (LaPointe and Hudson, 1985) due to poorer sampling of joints that are less than orthogonal to the orientation of the scanline is minimized. The procedure was to place orientations in $1^{\circ}$ bins and then correct the bin count by dividing by the sine of the angle between the joint strike and the scanline (Terzhagi, 1965). An issue with this correction is that, as the angle tends to zero, the correction tends to infinity and overestimates the fracture abundance. No formal procedure exists to eliminate this tendency, although various workers have used cut-off values for the angle of $5^{\circ}$ to $20^{\circ}$ for cessation of the application of the correction (Terzhagi, 1965; Priest, 1993). Our procedure to deal with this tendency was to use these data as an upper bound and uncorrected data as a lower bound. Third, the bin count was normalized for a scanline of 50-m length. Finally, the bin count was normalized to a common bed thickness (e.g. bed 1848 on the bench that has an average thickness of $17.6 \mathrm{~cm}$ ). This last step accounts for the variation of joint spacing as a function of bed thickness (e.g. Narr and Suppe, 1991).

Normalized joint density data at stations in subhorizontal beds are presented as number of joints per degree of strike for five $50 \mathrm{~m}$ scanlines that were combined to yield $250 \mathrm{~m}$ of scanline (Fig. 7a). Five peaks in the frequency versus orientation data represent five joint sets observed in the subhorizontal beds (Fig. 6a, Fig. 6b, and Fig. 7a). A sixth joint set (i.e. $J_{3}$ ) appears in one subhorizontal bed but is so poorly developed that it is not found as a peak in the frequency versus azimuth diagram (Fig. 7a).

The affect of inhomogeneous joint development is seen by comparing Fig. 6(a) and Fig. 7(a). In bed 1921, $J_{1}$ joints appear to be relatively abundant (Fig. 6a). Yet, when the five scanlines are combined (Fig. 7a), the abundance of $J_{1}$ joints decreases because they occur in only one scanline. Thus, $J_{1}$ is less common when considering the joint population in a larger rock volume involving several beds. 
(a)

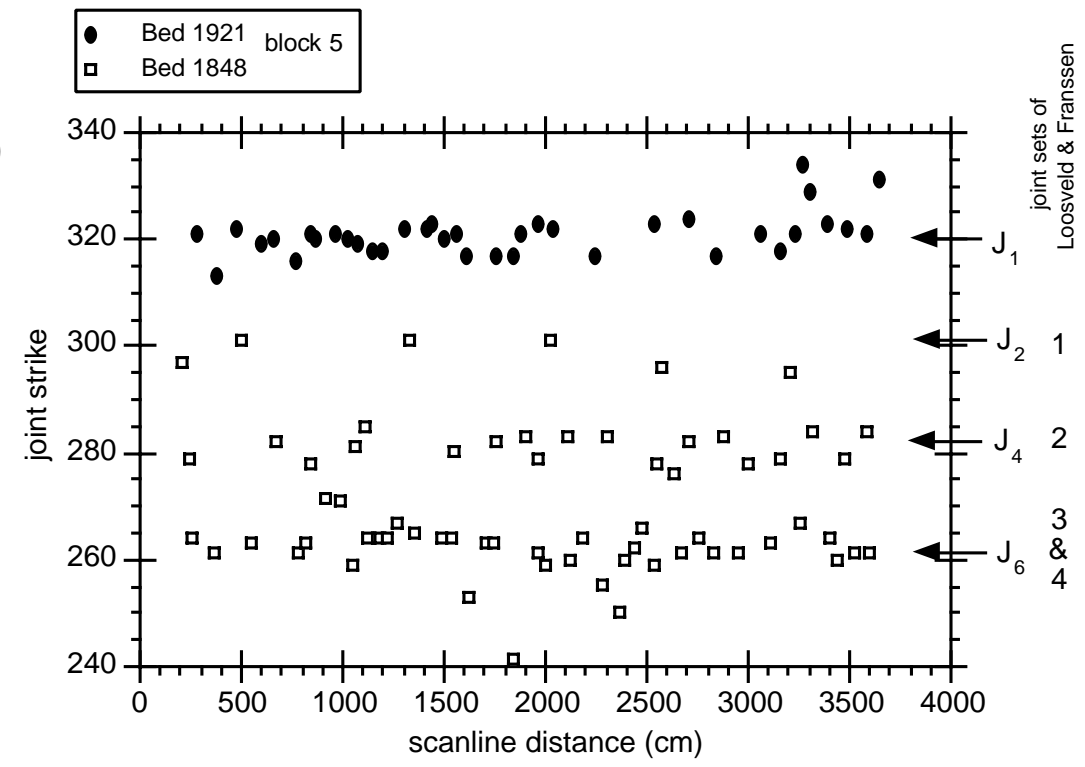

(b)

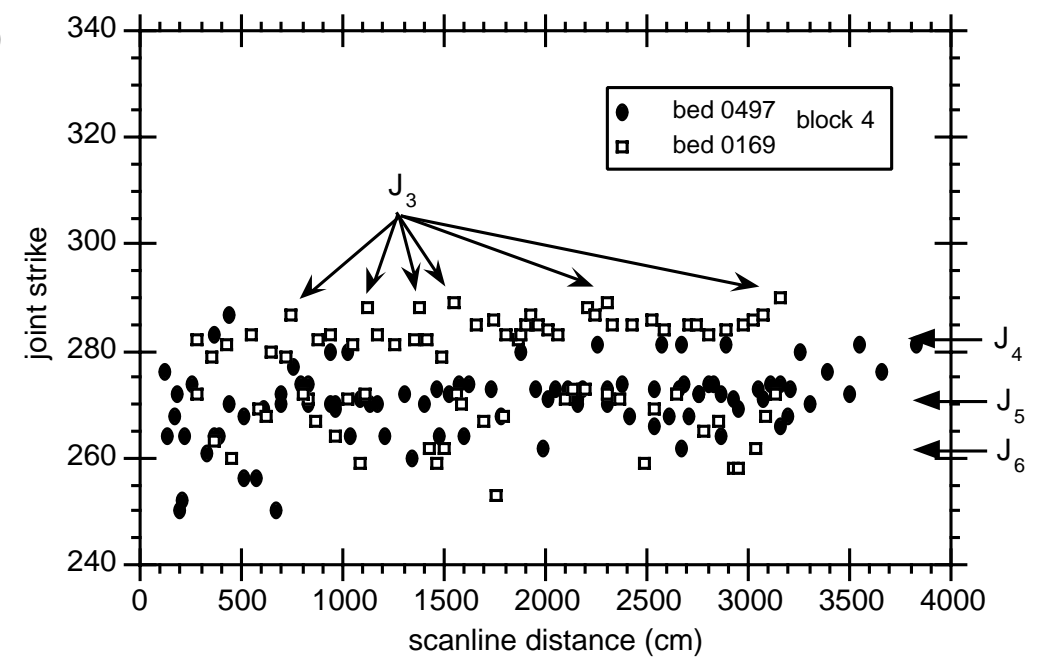

(c)

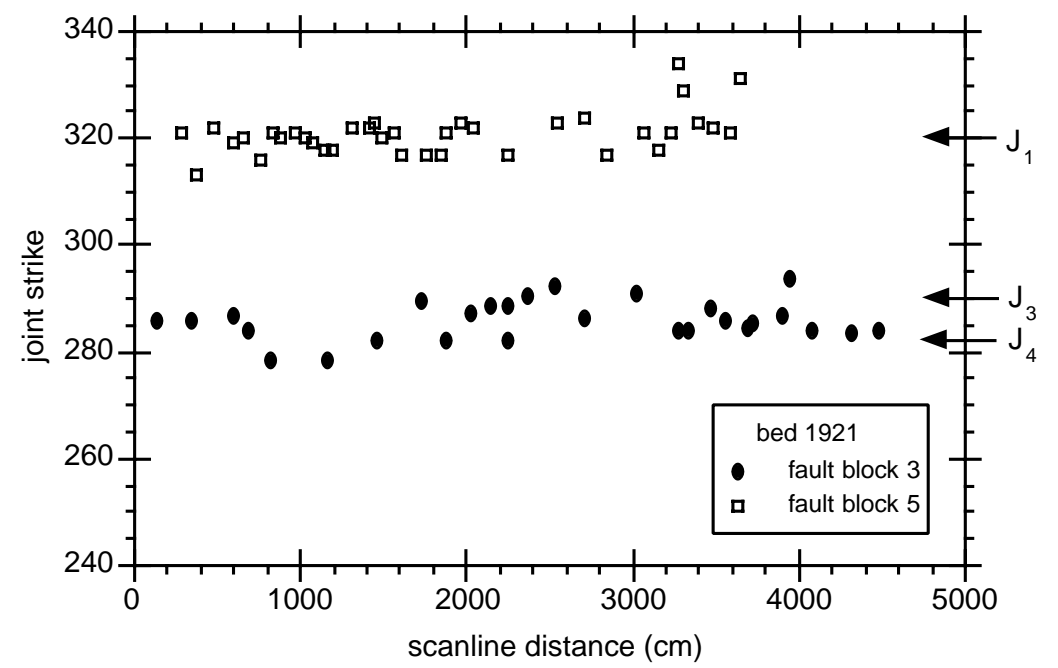

Fig. 6. (a) Joint strike versus distance for a scanline corrected to a scanline azimuth of $040^{\circ}$ for beds 1848 and 1921 on the bench north of fault 5 . (b) Joint strike versus distance for a scanline corrected to a scanline azimuth of $044^{\circ}$ for beds 0169 and 0497 in eastern fault block 4 . (c) Joint strike versus distance for bed 1921 for a scanline azimuth of $040^{\circ}$ for the bench north of fault 5 and $110^{\circ}$ in fault block 3 . 
(a)

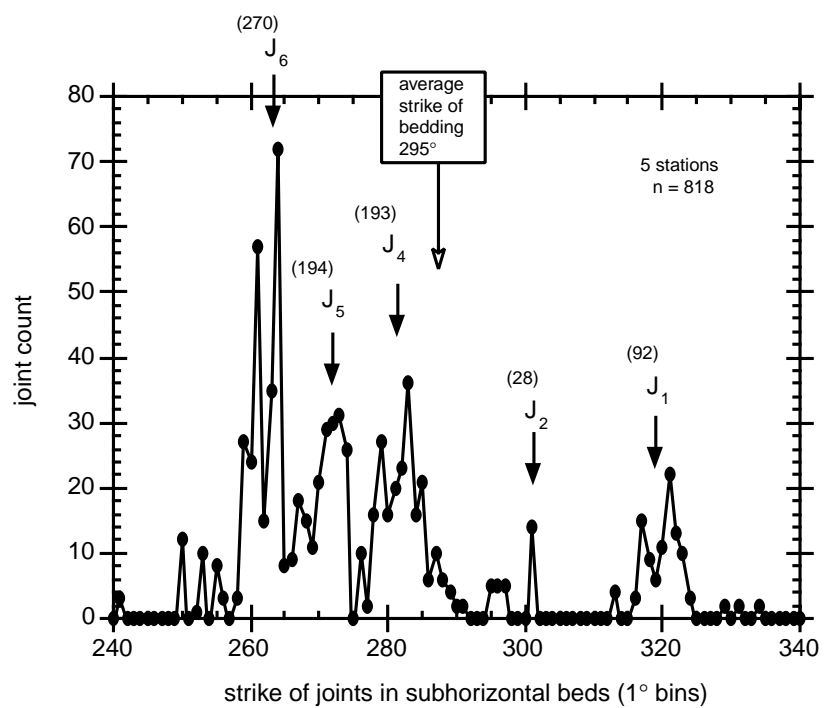

(b)

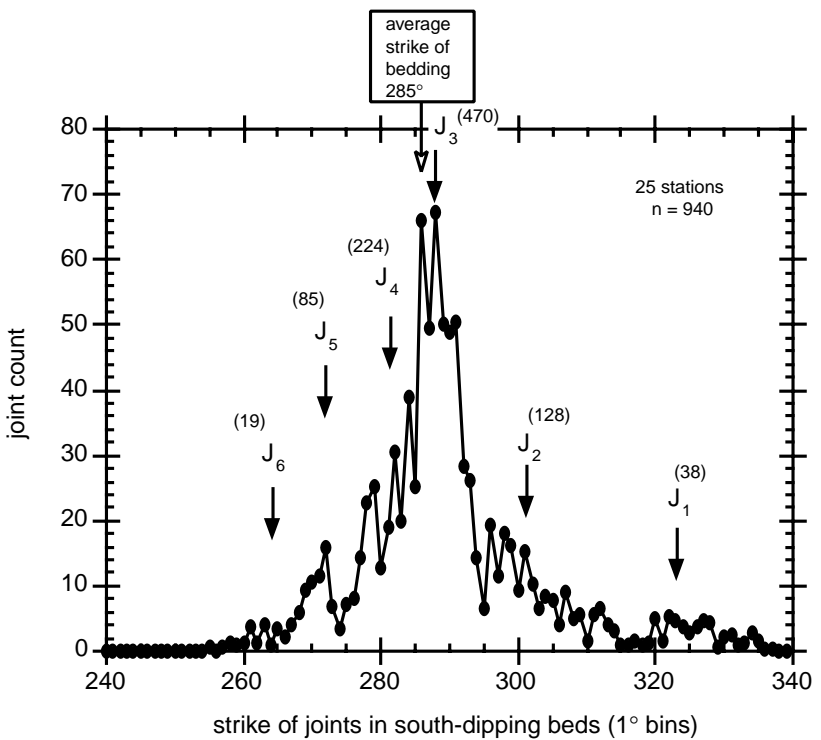

(c)

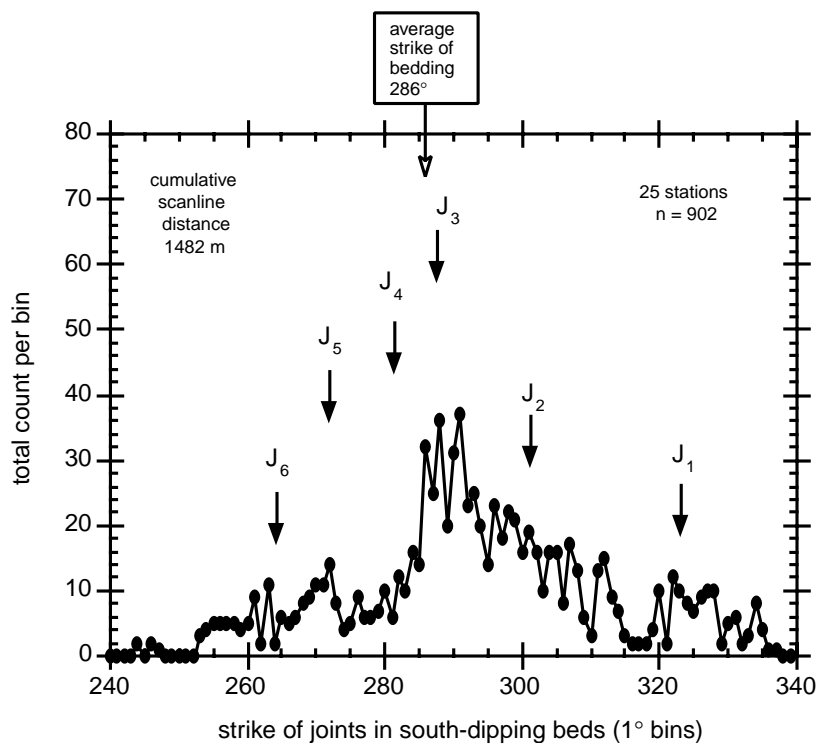

Fig. 7. Joint frequency versus joint strike. Joint count normalized to a $250-\mathrm{m}$ scanline with the data binned into $1^{\circ}$ intervals. (a) Subhorizontal beds in blocks 4 and 5. (b) Dipping beds of the Lilstock buttress anticline, in blocks 1, 3 and 4. (c) Binned data without normalizing joint data for either scanline length or scanline orientation, in blocks 1,3 and 4. 


\subsection{Joint sets in steeply-dipping beds}

Joints in the south-dipping limb of the Lilstock buttress anticline dip to the north as expected for beds that dip to the south (Fig. 5). Beds commonly carry more than one joint set but no beds carry the large number of joints sets found in bed 1848 of fault block 5 (Fig. 6a). To correlate joints in the south-dipping limb with our control sample, we rotated joints to their attitude in horizontal bedding. After rotation the joint-frequency data for steeply-tilted beds are normalized in the same manner as for subhorizontal beds (Fig. 7b). The joint orientation population in the south-dipping beds of Lilstock Beach is, indeed, different from the population in the subhorizontal beds (Fig. 7b vs. Fig. 7a). The most prominent joint set $\left(J_{3}\right)$ in the south-dipping beds is not identifiable as a peak in the binned data from the subhorizontal beds. $J_{3}$ is nearly parallel to the strike of bedding and the fold hinge of the Lilstock buttress anticline. To assure that the azimuthal correction for small angle between scanlines and joint strike did not artificially exaggerate the frequency of $J_{3}$ joints, the binned poles to joints are plotted prior to correction for scanline orientation (Fig. 7c). Even without an azimuthal correction, $J_{3}$ joints still appear as the most common set in the steeply-tilted beds.

\subsection{The orientations of joints relative to faults}

Members of the $J_{3}$ joint set (strike $290^{\circ}$ ) transect the fold and veins in a relay ramp in the western portion of fault block 3 (Fig. $4 \mathrm{~g}$ ). This relay ramp is evidence that $J_{3}$ joints post-date the early extension of the Bristol Channel. There are various relationships between $J_{3}$ joints and normal faults at Lilstock. For example, some systematic $J_{3}$ joints at Lilstock Beach cut through incipient high angle faults without being displaced by the faults (Fig. 4d). Other systematic $J_{3}$ joints abut high angle faults without appreciable deflection (Fig. 4e). Both faults are early calcite-filled normal faults that show no evidence of reverse-reactivation during Alpine contraction. Like the relay ramp in bed 1735 , the $J_{3}$ joints near these faults post-date the Mesozoic extension indicated by these normal faults.

The joint-orientation population varies from fault block to fault block. For example, bed 1921 appears in western block 3 dipping up to $43^{\circ}$ to the south compared with its slight dip to the north in the bench of block 5 . Within western block $3, J_{3}$ and $J_{4}$ appear without $J_{1}$, which is the only set in bed 1921 on the bench (Fig. 6c). This example is typical of the difference in joint patterns within the same bed from block to block. We interpret this common difference to mean that jointing took place after beds became isolated within individual fault blocks after at least some fault displacement. Because of the widespread occurrence of systematic joint sets within fault blocks, we conclude that the internal portions of fault blocks were unaffected by stress reorientation generated during fault slip. We also interpret these differences to allow the possibility that the jointing mechanism in the south-dipping limb of the Lilstock buttress anticline differed from that in the subhorizontal beds.

\subsection{The sequence of joint development}

Within subhorizontal bed 1848, the abutting sequence indicates that $J_{2}$ propagates before $J_{4}$ which propagates before $J_{6}$ (Fig. 4f). Assuming joints form parallel to regional $S_{\mathrm{H}}$ directions, this sequence shows the same anticlockwise reorientation of the remote stress field as seen throughout the eastern portion of the Bristol Channel (Rawnsley et al., 1998). One objective of our study was to determine whether this abutting sequence is also found in the steeply southdipping beds in the Lilstock buttress anticline.

The same anticlockwise sequence may be traced in bed 0497 from a subhorizontal orientation in block 4 into the south-dipping limb of the Lilstock buttress anticline (Fig. $4 \mathrm{~h}$ ). This is a rare example where $J_{3}$ abuts $J_{2}$. As the dip of bed 0497 steepens, $J_{2}$ is absent and $J_{4}$ abuts $J_{3}$. Another example of this anticlockwise sequence of joint formation is found in bed 3883 , with dips of up to $30^{\circ}$ in the central and western portions of fault block 1 (Fig. 5d). Other beds also show a clear anticlockwise age sequence, but the joint sets involved are not all the same (Table 1).

Based on abutting relationships, the anticlockwise age sequence for joints is present in south-dipping beds, but this geometry is apparently less common than on subhorizontal surfaces (Table 1). Determination of this sequence requires the presence of two or more joint sets abutting at a station, but relatively few stations contain such geometries, partially because the exposed dimension of bedding surfaces parallel to bed dip are small (e.g. Fig. $4 \mathrm{~d}$, e, and h). Often, a bed instead contains two groups of joints with different orientations that are developed in different portions of the exposed bedding surface along strike. In such cases, it is difficult to determine whether the groups are separate sets or are from a single curving set as is seen near faults. Also, more than half of the samples from the southdipping beds have only one systematic joint set, precluding the chance to determine timing relationships (Table 1).

When considering relative joint abundance, the general rule is that beds containing $J_{1}$ or $J_{2}$ joints lack $J_{3}$ joints. Where $J_{3}$ joints are found, they are the oldest joints and strike closest to bedding strike (Table 1). Thus, no compelling evidence exists for the timing of $J_{3}$ relative to $J_{1}$ and $J_{2}$ because they do not occur together except along a small portion of bed 0497 (Fig. 4h).

The distribution of joints in the south-dipping limb of the Lilstock buttress anticline also correlates to stratigraphic and structural position. $J_{1}$ and $J_{2}$ joints are high in the section and located exclusively in block $1 . J_{3}$ and $J_{4}$ joints are most common in the middle of the section located in blocks 3 and $4 . J_{3}$ joints are also best developed near the reverse fault interpreted to be responsible for the development of the Lilstock buttress anticline. $J_{5}$ and $J_{6}$ joints are 
Table 1

Joint development: All stations in south limb of buttress anticline

\begin{tabular}{|c|c|c|c|c|c|c|c|c|}
\hline Bed & BGS Beds & Fault Block & $J_{1}$ & $J_{2}$ & $J_{3}$ & $J_{4}$ & $J_{5}$ & Sequence* \\
\hline 4074 & 161 & 1 & $\mathrm{X}$ & & & & & \\
\hline 4005 & 159 & 1 & $\mathrm{X}$ & $\mathrm{X}$ & & & & CCW \\
\hline 3883 & 157 & 1 & $X$ & $\mathrm{X}$ & & & $X$ & $\mathrm{CCW}$ \\
\hline 3770 & 155 & 1 & & & & $X$ & & \\
\hline 3590 & 151 & 1 & $\mathrm{X}$ & & & & & \\
\hline 3492 & 149 & 1 & $\mathrm{X}$ & & & & $X$ & separate \\
\hline 3427 & 147 & 1 & $X$ & $\mathrm{X}$ & & & & $\mathrm{CCW}$ \\
\hline 3206 & 144 & 1 & & & $\mathrm{X}$ & & & \\
\hline 3185 & 142 & 3 & & & $\mathrm{X}$ & & & \\
\hline 3133BC & 140 & 1 & & $\mathrm{X}$ & & & $X$ & separate \\
\hline 3133A & 140 & 3 & & & $\mathrm{X}$ & & & \\
\hline 3044 & 138 & 3 & & & $\mathrm{X}$ & & & \\
\hline 2742D & 134 & 3 & & & $\mathrm{X}$ & & & \\
\hline $2742 \mathrm{ABC}$ & 134 & 1 & & & $X$ & $\mathrm{X}$ & & $\mathrm{CCW}$ \\
\hline 2429B & 126 & 4 & & & $\mathrm{X}$ & & $X$ & $\mathrm{CCW}$ \\
\hline 2429AC & 126 & 1 & & $\mathrm{X}$ or & $\mathrm{X}$ & & & separate \\
\hline 2228 & $121-123$ & 4 & & $\mathrm{X}$ & & & & \\
\hline 1921A & 114 & 3 & & & $X$ & $\mathrm{X}$ & & separate \\
\hline $1848 \mathrm{E}$ & 109 & 3 & & $\mathrm{X}$ & & & & \\
\hline $1848 \mathrm{CD}$ & 109 & 3 & & & $\mathrm{X}$ & & $X$ & separate \\
\hline $1848 \mathrm{~A}$ & 109 & 4 & & & $X$ & & $X$ & $\mathrm{CCW}$ \\
\hline $1735 \mathrm{C}$ & 105 & 3 & & & $\mathrm{X}$ & & & \\
\hline $1735 \mathrm{AB}$ & 105 & 4 & & $X$ & & & $X$ & separate \\
\hline 1700 & 103 & 3 & & & & $\mathrm{X}$ & & \\
\hline 1599AB & 101 & 4 & & $\mathrm{X}$ & & & & \\
\hline 1152 & 95 & 4 & & & & & $X$ & \\
\hline 0678 & 88 & 4 & & & $\mathrm{X}$ & & $X$ & separate \\
\hline 0609 & 85 & 4 & & & & & $X$ & \\
\hline 0497D & 83 & 4 & & & & $X$ & $X$ & separate \\
\hline 0497B & 83 & 4 & & & $\mathrm{X}$ & & $X$ & CCW \\
\hline
\end{tabular}

* CCW - joints that abut with an anticlockwise sense of development. Separate-joints that have developed in separate regions of a bed.

most common low in the section and nearest the anticlinehinge where beds dip shallowly.

\subsection{The attitude of joints relative to bedding}

Joints contained within competent beds are typically perpendicular to bedding in many field settings (Hancock, 1985). However, joints of sets $J_{1}$ to $J_{5}$ in the south-dipping beds of the Lilstock buttress anticline are not perpendicular to bedding. These joints consistently dip north when bedding is restored to the horizontal (e.g. $J_{3}$ joints in Fig. 5c). Correspondingly, their poles plunge south, towards the European Alpine hinterland, when bedding is restored to the horizontal. The joint-pole plunge angle is used to define the "tilt towards the hinterland" for the joint sets (Fig. 8). The tilt increases from $3^{\circ}$ for the older $J_{1}$ joints to $7^{\circ}$ for younger $J_{5}$ joints. $J_{3}$ joints occur only in the south-dipping limb of the anticline, so are considered to be of particular interest in interpreting the geometry and mechanics of fold and joint development. The geometric characteristics of the $J_{3}$ joints are therefore used to guide a mechanical analysis in search for a cause of joint tilt.

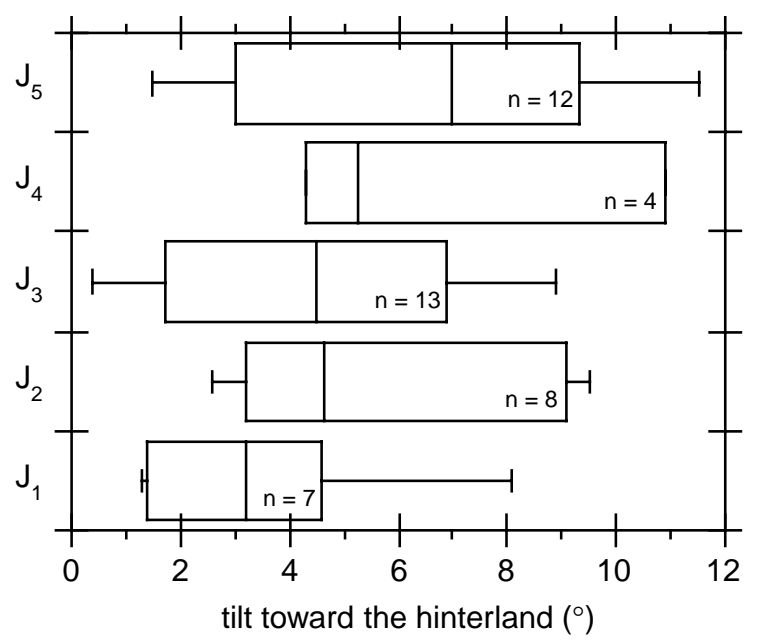

Fig. 8. Box plot for the tilt of the vector mean pole to joints from 44 joint populations in south-dipping beds of the Lilstock buttress anticline. The tilt is measured downward in the direction of the hinterland (i.e. southern Europe) relative to bedding when it is restored to horizontal. The centerline of each box represents the $50^{\text {th }}$ percentile of the data while the left and right edges of the boxes represent the $25^{\text {th }}$ and $75^{\text {th }}$ percentile of the data, respectively.

\section{Stress state in south-dipping limestone beds during Alpine inversion}

\subsection{The association between $J_{3}$ joints and the Lilstock buttress anticline}

Six observations lead us to conclude that $J_{3}$ joints in the south-dipping beds at Lilstock Beach propagated during the development of the Lilstock buttress anticline reflecting Alpine inversion:

1. $J_{3}$ joints are rare in the subhorizontal beds of Lilstock Beach but are the most common set in the steep limb of the Lilstock buttress anticline. The mechanism driving $J_{3}$ jointing must involve higher strain on the limbs of folds and little strain in the hinge area.

2. $J_{3}$ joints are most common in the vicinity of Fault 4, which was reversed to form the Lilstock buttress anticline. This spatial association with a high-angle reverse fault points to the possibility that $J_{3}$ jointing was contemporaneous with Alpine inversion.

3. Poles to joints in the southern limb of the Lilstock buttress anticline consistently plunge toward the hinterland relative to bedding. The plunge azimuth is parallel to the inferred compression direction $\left(019^{\circ}\right)$ during Alpine inversion (Kelly et al., 1998). The consistency of tilt to bedding is interpreted to indicate that joints could have developed during an imposed shear couple on bedding.

4. The strike of $J_{3}$ is nearly parallel to bedding strike in the south-dipping limb of the anticline (Fig. 7b). Strikeparallel joints are commonly associated with outer-arc extension of beds during folding (e.g. Van Hise, 1896; 
Hancock, 1985) but outer-arc extension by tangential longitudinal strain folding is greater in the hinge area and absent at inflection points in the limbs (Price and Cosgrove, 1990).

5. $J_{3}$ joints completely cut through beds and thus, differ from joints that form by outer-arc extension above a neutral fiber (Van Hise, 1896).

6. $J_{3}$ joints do not propagate in a bed with $J_{1}$ or $J_{2}$ joints and vice versa (Table 1). Whatever mechanism was responsible for $J_{3}$, it is clear that $J_{3}$ propagated in neither subhorizontal beds nor previously jointed beds.

Alpine inversion was driven by a remote $S_{\mathrm{H}}$ directed about $019^{\circ}$ (Kelly et al., 1998). A remote $S_{\mathrm{H}}$ oriented at or about $019^{\circ}$ presents a mechanical paradox if $J_{3}$ joints propagated during parallel folding, because they opened in a direction that is at a small angle to $S_{\mathrm{H}}$. If controlled by the remote stress, $J_{3}$ joints would open in a plane that contains $S_{\mathrm{H}}$. The paradox here is that $J_{3}$ joints open against this remote compressive $S_{\mathrm{H}}$ and, thus, must be controlled by a local stress. Our challenge is to find the set of boundary conditions that generate a local tensile stress when a regional compressive stress is superimposed on the limestone-shale package of the Lilstock buttress anticline. To understand the tilt of joints in the south-dipping beds of the Lilstock buttress anticline and their ability to open subperpendicular to $S_{\mathrm{H}}$, we apply a simple finite element model to demonstrate the development of a shear couple on limestone beds during parallel folding by flexural flow of the shale interlayers. If our premise is correct about the genetic relationship between the orientation of $J_{3}$ joints and the shear couple on limestone beds, we can identify an orientation for $S_{\mathrm{H}}$ associated with these boundary conditions. To anticipate our result, remote $S_{\mathrm{H}}$ controlling $J_{3}$ joints is in the same direction as the remote $S_{\mathrm{H}}$ driving the conjugate strike-slip faults during Alpine inversion.

\subsection{Stress configuration in limestone beds during the development of the Lilstock buttress anticline as a flexural- flow fold}

The distinction in the literature between flexural-slip and flexural-flow folds is hazy when incompetent layers are thick relative to competent layers. Ghosh (1993) points out that "If the thickness of the incompetent layers become vanishingly small the folds become flexural-slip folds". Otherwise, the Lilstock anticline is a flexural-flow fold (Donath and Parker, 1964). Ramsay and Huber (1987) are more restrictive in defining flexural-flow folds as those folds showing a continuously distributed simple shear. In our model, it is the elastic portion of the simple shear in limestone layers that controls the orientation of joint propagation. While simple shear is discontinuous from layer to layer, the amount of shear between limestone layers is not nearly as large as would be the case for flexural-slip folds with thin shale interlayers. Our model resembles the view of
Hudleston et al. (1996) that a flexural-flow fold consists of alternating layers that have a large viscosity contrast.

The Lilstock buttress anticline developed in a sequence of interbedded limestones and shales, which according to compilations of mechanical properties in the literature (e.g. Hatheway and Kiersch, 1982), should be characterized by a significant contrast between the elastic properties of the limestone and shale. This lithological pair is commonly associated with flexural-slip folding in which the more brittle limestone beds slip on ductile shale interlayers (e.g. Ramsay and Huber, 1987). Displacement also occurs by layer-parallel shearing of the shale during flexural-flow folding. Often, the shale interlayers are thin relative to the carbonate beds but at Lilstock the opposite is true. We suspect that thick shale layers obscure all evidence for slip by simple shear strain within the shale, if present, largely because the shear strain could be relatively small and because such strain markers as stretched ammonites are rare. Nevertheless, as the beds of the anticline were tilted they were subject to a shear couple arising from the regional $S_{\mathrm{H}}$, assuming for simplicity that $S_{\mathrm{H}}$ and $S_{\mathrm{v}}$ are principal stresses. This assumption of a remote horizontal principal stress is supported by horizontal slip on the conjugate strikeslip faults active during Alpine inversion, and by slickenside lineation orientations on the inverted normal faults (Kelly et al., 1998).

Joints are assumed to propagate in an elastic stress field (Pollard and Segall, 1987). We therefore map the stress fields induced in an elastic medium under loading configurations consistent with a shear couple developed during layer-parallel shear. Our models are 2D finite element analyses using the interactive fracture analysis program FRANC (Wawrzynek and Ingraffea, 1987). We use a model mesh of quadratic, isoparametric elements with boundary conditions similar those shown in Fig. 9. A three-layer model simulates a limestone bed of the Blue Lias between two shale layers. The model was scaled to place a $30 \mathrm{~cm}$-thick bed in the central portion of a package $40 \mathrm{~m}$ thick by $200 \mathrm{~m}$ wide, the dimension of the southdipping limb of the Lilstock buttress anticline. The total model consists of a rectangular grid with approximately $10^{5}$ elements. Early in our investigation we discovered that three bed model was sufficient because adjacent limestone beds had no effect as long as the interlayered shale was twice as thick as the limestone beds, a situation typical of Lilstock.

A global vertical stress $\left(S_{\mathrm{V}}\right)$ of $25 \mathrm{MPa}$ was applied to the top boundary of the model to simulate a depth of burial of 1 $\mathrm{km}$, the approximate depth of the Blue Lias during Alpine inversion (John Cosgrove, personal communication, 1999). The bottom boundary was fixed. Different global horizontal stresses were applied to the top boundary to test for the effect of stress ratio (i.e. $R=S_{\mathrm{H}} / S_{\mathrm{v}}$ ) on the elastic stress field generated within the three-bed model. Horizontal stress $\left(S_{\mathrm{H}}\right)$ was varied in $25 \mathrm{MPa}$ increments from 25 to $100 \mathrm{MPa}$ $(1=\mathrm{R}=4)$. To simulate layer-parallel shear by flexural 


$$
\text { Contours of Maximum Tensile Stress } \quad R=1.66\left(\frac{-41.5 \mathrm{MPa}}{-25 \mathrm{MPa}}\right)
$$

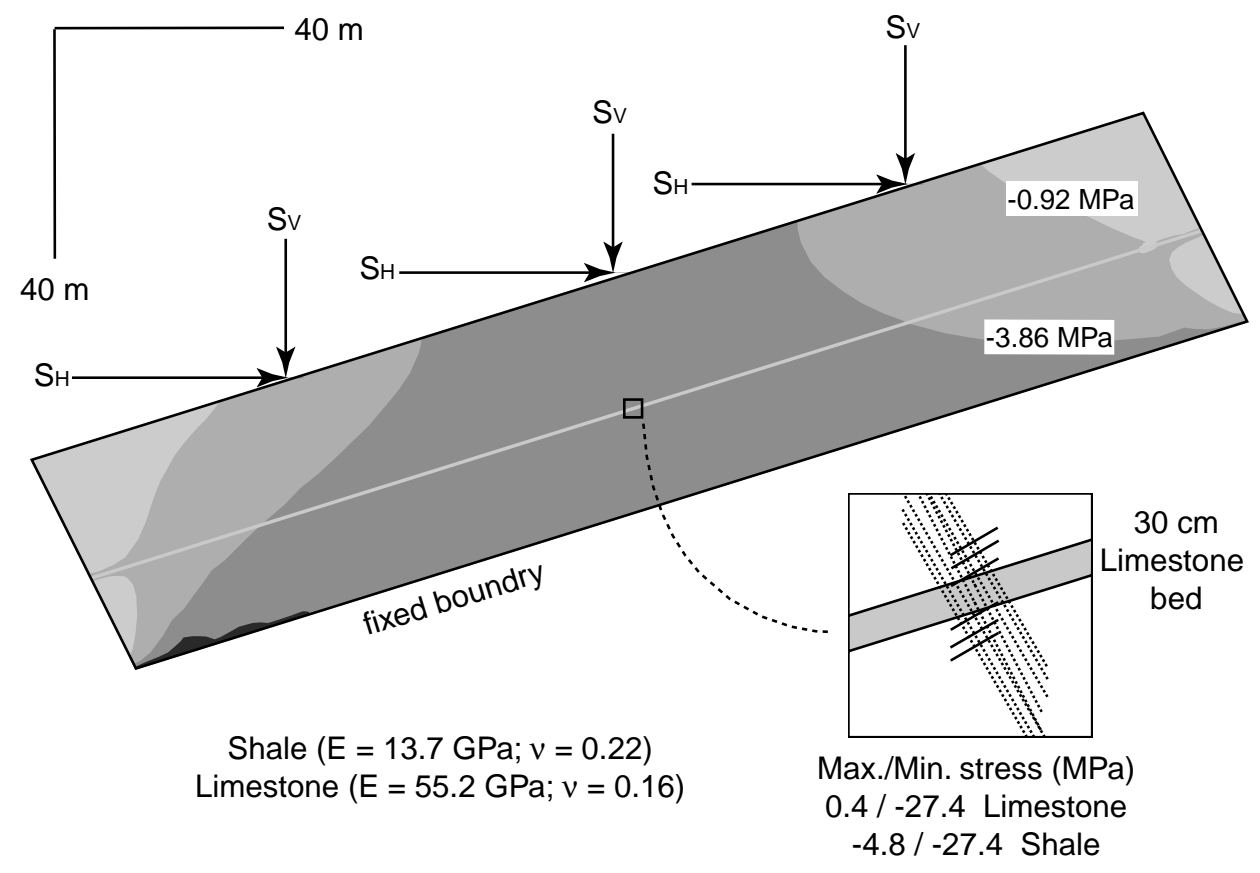

Fig. 9. A three-bed model of the limb of the Lilstock buttress anticline contoured for $\sigma_{3}$ (compressive stress is negative). The top surface is loaded as indicated with the bottom boundary fixed and the left and right boundaries free to shear. The thin middle bed is a $30 \mathrm{~cm}$ limestone with elastic properties as indicated. In close-up inset the orientation of the local principal stresses are indicated with $\sigma_{1}=-27.4 \mathrm{MPa}$ and $\sigma_{3}=0.4 \mathrm{MPa}$ (limestone), $=-4.8 \mathrm{MPa}$ (shale). Tensile stress is indicated by a solid line and compressive stress is indicated by a dashed line.

flow, the ends of the model were unbounded. The model was tilted several degrees, allowing the generation of a significant shear traction on the limestone beds due to the superposition of $S_{\mathrm{H}}$ and $S_{\mathrm{v}}$.

We draw upon two sources to estimate the Young's moduli $(E)$ and Poisson's ratios $(\nu)$ of the rocks within the Lilstock buttress anticline: in situ geophysical logs and laboratory tests. Because the beds at Lilstock are too thin to register as separate beds using typical sonic logging tools, we must find a thicker analog. As an alternate, we selected the properties of the Tully Limestone and Geneseo black shale in Devonian rocks of the Appalachian Plateau (Plumb et al., 1991). The properties of the limestone and shale are $E_{\mathrm{ls}}=76 \mathrm{GPa}$ plus $\nu_{\mathrm{ls}}=0.31$ and $E_{\mathrm{sh}}=20 \mathrm{GPa}$ plus $\nu_{\mathrm{sh}}=0.35$. A compilation of laboratory tests gives median values for Young's modulus that are similar to the field values (i.e. $E_{\mathrm{ls}}=58.5 \mathrm{GPa}$ and $E_{\mathrm{sh}}=15.9 \mathrm{GPa}$ ) but somewhat lower values for Poisson's ratio (i.e. $\nu_{1 \mathrm{~s}}=0.22$ and $\nu_{\text {sh }}=0.16$ ) (e.g. Blair, 1955, 1956; Hatheway and Kiersch, 1982; Fischer, 1994).

A discrepancy in the properties of the limestone and shale is the reversal of relative magnitude of $\nu$ between the field and laboratory. For our initial models, we chose values close to the median of laboratory tests but set the relative magnitude of $\nu$ so that they reflect field conditions following Plumb et al. (1991) (i.e., $E_{\mathrm{ls}}=55.2 \mathrm{GPa}$ plus $\nu_{\mathrm{ls}}=0.16$ and $E_{\mathrm{sh}}=13.7 \mathrm{GPa}$ plus $\nu_{\mathrm{sh}}=0.22$ ). These values for the properties of limestone and shale are somewhat arbitrary for the convenience of modeling but seem to be reasonable estimates of the in situ conditions based on geophysical and laboratory data. The effect of $\nu$ was also investigated by reversing the values for limestone $\left(\nu_{\mathrm{ls}}=0.22\right)$ and shale $\left(\nu_{\mathrm{sh}}=0.16\right)$

Fig. 9 shows a contour map of the maximum tensile stress (i.e. $\sigma_{3}$ with tensile stress positive) generated in beds dipping at $17^{\circ}$ and subject to a stress ratio (i.e. $R=S_{\mathrm{H}} / S_{\mathrm{v}}$ ) of 1.66. Our model has a length to height ratio of 5 , which is sufficient to carry end conditions away from the central portion of the model. We are concerned with the stress within a $3 \mathrm{~m}^{2}$ square element within the central portion of the model. Our initial models show that the elastic contrast between the limestone and shale beds leads to a tensile $\sigma_{3}$ within the limestone layers for values of $R$ between one and four and $\nu_{\mathrm{sh}}>\nu_{\mathrm{ls}}$. Tensile stress is generated as long as flexural flow is permitted under the tractions specified in Fig. 9. Fixing the ends of the model to prevent layer-parallel shear strain, of course, will not permit the generation of tensile stresses in the stiff beds. A model with fixed ends is inconsistent with folding by flexural flow (Price and Cosgrove, 1990).

Not only is the local $\sigma_{3}$ tensile in the stiff beds under conditions of flexural-flow folding, but $\sigma_{3}$ cants downward relative to bedding in the direction of the horizontal stress (Figs. 9 and 10). When local $\sigma_{3}$ is tensile, joints propagate 

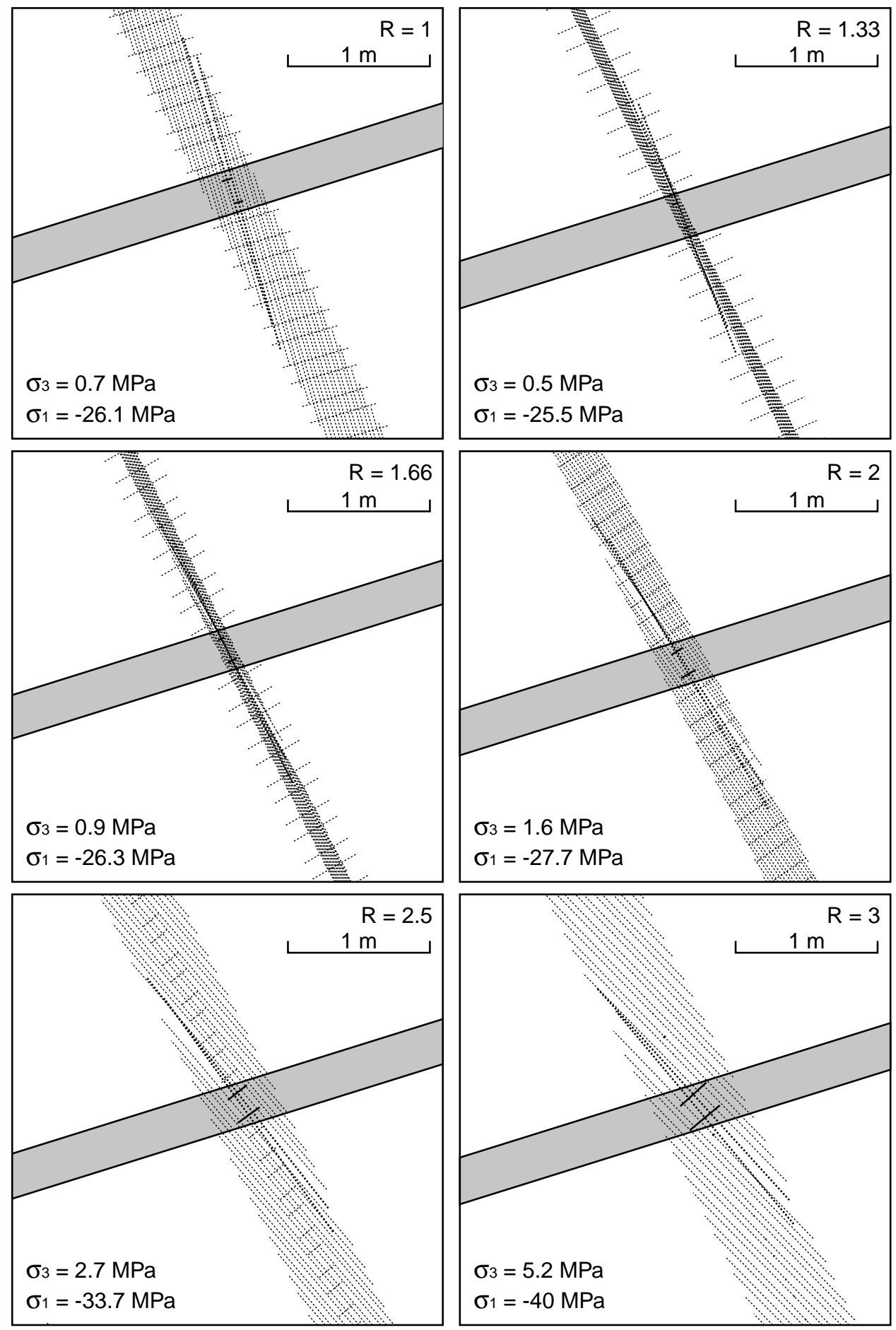

Fig. 10. Six models for the orientation of stress in a $30-\mathrm{cm}$ thick limestone bed dipping $17^{\circ}$. Elastic properties as in Fig. 9 . Tensile stress is indicated by a solid line and compressive stress is indicated by a dashed line.

parallel to local $\sigma_{1}$, which is always compressive in our models (the dashed lines in Figs. 9 and 10). Local $\sigma_{1}$ refracts modestly at the boundary between the limestone and shale beds, becoming steeper in the stiffer limestone bed (Figs. 9 and 10).

We ran a series of models to test for the affect of $R$ on controlling the tilt of the local $\sigma_{1}$, and hence the predicted attitude of $J_{3}$ joints with respect to bedding. As $R$ is increased from 1 to 4 , the local $\sigma_{1}$ tilts at an incrementally larger angle toward the foreland in both the shale and limestone beds. The magnitude of tensile $\sigma_{3}$ in limestone beds becomes larger ( $0.5 \mathrm{MPa}$ to $5.2 \mathrm{MPa})$ as $R$ increases from 1 to 3 (Fig. 10). At $R \approx 4, \sigma_{3}$ in shale near the limestone bed also becomes tensile. We ran the same series of tests for 


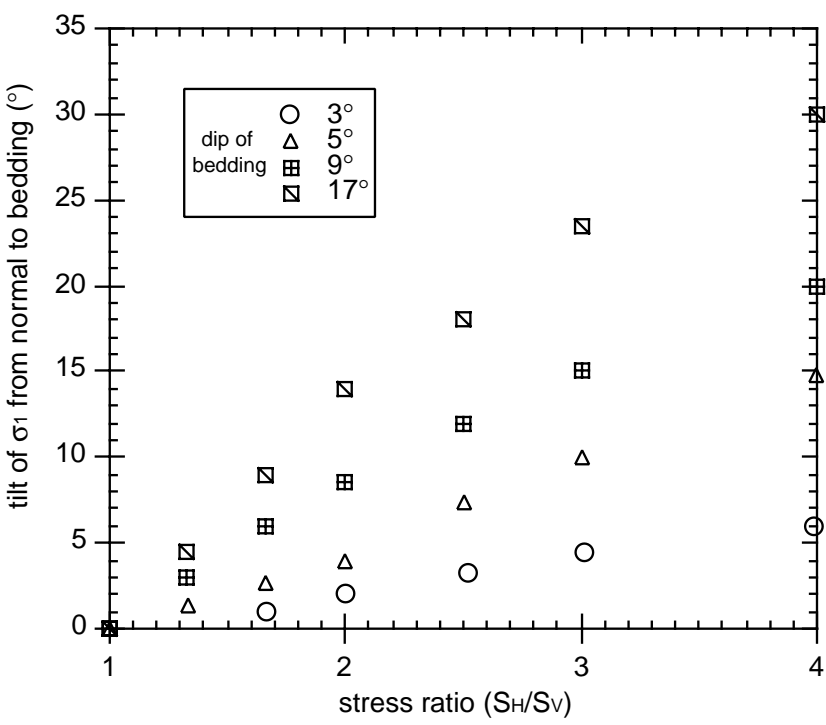

Fig. 11. Tilt of the local $\sigma_{1}$ from normal to bedding as a function of stress ratio $(R)$ for beds dipping $3^{\circ}, 5^{\circ}, 9^{\circ}$, and $17^{\circ}$. Elastic properties as in Fig. 9.

beds dipping at $3^{\circ}, 5^{\circ}$, and $9^{\circ}$. For each bed dip, the tilt of the joint plane toward the hinterland (i.e. local $\sigma_{1}$ ) increases for increasing $R$. The rate of increase in tilt is larger for more steeply dipping beds (Fig. 11).

We also ran a series of models to test for the effect of $\nu$ by setting $\nu_{\mathrm{ls}}=0.22$ and $\nu_{\mathrm{sh}}=0.16$, with the following results. First, tensile $\sigma_{3}$ is not achieved in the limestone beds until $R$ approaches 4 . Second, $\sigma_{3}$ in the limestone beds remains more compressive relative to $\sigma_{3}$ in the adjacent shale beds at all values of $R$. Third, the refraction of stress through the limestone bed has the opposite sense of rotation. Fourth, tension is achieved in the shale at a lower $R$ than required for tension in the limestone. Fifth, when tension is achieved in the limestone bed for $R=4$, joints would tilt more than $20^{\circ}$ toward the hinterland relative to bedding, a situation not consistent with joint orientation data from Lilstock. We conclude that $\nu$ was less in limestones than shales because more joints would otherwise occur in the shales than in the limestones and because $\nu_{\mathrm{ls}}>\nu_{\mathrm{sh}}$ is inconsistent with in situ geophysical logging data.

\section{Discussion}

\subsection{Other examples of fracture development during flexural-flow folding}

Flexural-flow appears to be a common process in folds (e.g. Ramsay, 1962, 1967). Our model predicts fanning joint patterns that are similar to the strongly-convergent dip isogons shown by class 1A folds of Ramsay (1967; fig. 724). Similar patterns of joints within flexural-flow folds are shown by Hills (1963; fig. VIII-14B) and by Whitten (1966; fig. 140). Balk (1937) describes similar fanning patterns of joints developed in country rocks above plutons.
The literature also contains examples of veins that are tilted relative to bedding (e.g. Ramsay, 1967; fig. 7-58 and Price and Cosgrove, 1990; fig. 13.6). Ramsay and Huber (1987, p. 453) show "rotated and folded quartz filled extension veins in alternating sandstones and shales" from Cornwall, England. The rotation of the veins in the shale interlayers gives the sense of flexural-slip, and the fractures in the brittle beds tilt toward the direction of local $\sigma_{1}$ and are antithetic to the shear sense. Price and Cosgrove (1990; fig. 17.30) also show fracture cleavage, which they attribute to hydraulic fracturing, with similar relationships to folds as do the joints in the Lilstock buttress anticline. The development of strongly convergent fans of joints, veins and fracture cleavage all suggest that layer-parallel shear is common with the development of minor fractures during flexuralflow folding.

\subsection{Joint propagation at depth without the benefit of high fluid pressure}

Joint development at depth is often attributed to high fluid pressures (Secor, 1965; Engelder and Lacazette, 1990; Engelder and Fischer, 1996) unless the beds are extended as composite layers with different elastic properties (Hobbs, 1967; Gross et al., 1995). Our model for the generation of tensile stresses during flexural-flow is a variation on the composite layer model first proposed by Hobbs (1967). An important consequence of our model is that compressive stresses are capable of generating local tensile stresses in the stiff layers of a composite, where bounding surfaces are subject to a shear traction as would be the case for flexuralflow folding. In this case, natural hydraulic fracturing under conditions of high fluid pressure is not the only mechanism capable of driving joint propagation at depth. We favor the flexural-flow mechanism over hydraulic fracturing because: 1) joints with tilt occur only in dipping rocks of the fold limbs, and 2) as predicted by our new model, joints are not orthogonal to bedding.

The implication of our model for the Lilstock buttress anticline is that joint (and vein) growth in the limbs of flexural-flow folds should have several distinct characteristics. The joints should extend through the entire bed, should be non-orthogonal with bedding, and poles to joint should tilt away from (i.e. joints dip toward) the anticlinal axial plane.

\subsection{Stress ratio and frictional slip}

Laboratory values of friction (Zoback and Healy, 1984) predict that fault slip occurs when $R=3$. We can use this stress ratio and the hinterland tilt of joints to predict the dip of bedding at the time of the onset of jointing (Fig. 11). Our model predicts that $J_{3}$ joints with a tilt of about $4^{\circ}$ should have propagated by the time beds had been upfolded to have a dip of $3^{\circ}$. If faults of the Alpine inversion slipped under low friction, $R$ could have been $<3$. For example, if $R=1.33$ during Alpine inversion due to low friction faults, 
a hinterland tilt of $4^{\circ}$ could indicate jointing in beds with a dip of as much as $17^{\circ}$.

Our flexural-flow model may be applied outside the immediate area of the Lilstock buttress anticline. During the extensional phase of the Bristol Channel tectonics, large blocks throughout the basin were slightly tilted (Dart, et al., 1995). Bedding of the Bristol Channel could have entered the Alpine inversion phase with a modest dip. Our analysis indicates that tensile stress can be generated in beds dipping at less than $2^{\circ}$, particularly if $\nu_{\mathrm{ls}}<\nu_{\mathrm{sh}}$. Many of the jointed outcrops on both the north and south shores of the Bristol Channel have a gentle dip that would have favored joint propagation during inversion tectonics. Joints not orthogonal to bedding have been recorded at Lavernock Point, South Wales, by Rawnsley et al. (1998).

\section{Conclusions}

At Lilstock Beach, a number of joint sets in the limestones beds of the Jurassic Blue Lias cluster about the strike of the axes of the Lilstock buttress anticline, including $J_{1}$ $\left(330^{\circ}-310^{\circ}\right), J_{2}\left(310^{\circ}-295^{\circ}\right), J_{3}\left(295^{\circ}-285^{\circ}\right), J_{4}\left(285^{\circ}-\right.$ $\left.275^{\circ}\right), J_{5}\left(275^{\circ}-265^{\circ}\right)$, and $J_{6}\left(<265^{\circ}\right)$. In subhorizontal beds, including those near the hinge surface of the Lilstock buttress anticline, $J_{3}$ joints are rare, whereas $J_{2}, J_{4}, J_{5}$, and $J_{6}$ abut to indicate an anticlockwise sequence of development. In the south-dipping beds of the anticline, $J_{3}$ joints are the most frequent in the vicinity of the reverse fault responsible for the anticline. $J_{3}$ joints are absent where $J_{1}$ and $J_{2}$ joints are present further from the anticlinal hinge of the anticline and higher in the stratigraphic section. $J_{3}$ joints in the southdipping beds of the Lilstock buttress anticline are not perpendicular to bedding, but have poles that plunge several degrees towards the south when bedding is restored to horizontal.

The mechanism for jointing must be consistent with: 1) a tilt of the $J_{3}$ joints relative to bedding on the south flank of a buttress anticline, and 2) a greater frequency of $J_{3}$ joints on the south-dipping limb versus the axial region of the buttress anticline. These two characteristics indicate propagation of $J_{3}$ joints during folding (i.e. before beds reach their present tilt). These conditions are satisfied in a model for shear of interlayered limestone-shale beds during flexural-flow folding, where local tensile stresses are generated within a regional stress field capable of driving inversion tectonics. Such tensile stresses will drive joints completely through beds rather than arresting at a neutral surface associated with outer-arc extension. In our model, joints can open against the direction of the maximum compressive stress under conditions where external tractions are compressive.

Our model indicates that at least some of the joints at Lilstock formed during the main Alpine inversion (cf. Rawnsley et al., 1998). It also shows that joints that are parallel to a fold hinge may form on the limbs during flexural-flow folding and not in the hinge region as a consequence of outer-arc extension during tangential longitudinal strain folding.

\section{Acknowledgements}

Paul Hancock first introduced TE to the wonderful Lilstock outcrop more than 15 years ago. This trip was the beginning of a fruitful collaboration that lead to our work on neotectonic joints (Hancock and Engelder, 1989). Our collaboration reached its zenith when Paul and his wife, Ann, hosted Jan Engelder and TE in their lovely Georgian row house in Bristol after our field campaign at Lilstock during the summer of 1997. We only wish that Paul could have seen the fruits of our work at Lilstock. We thank John Cosgrove and Peter Connelly whose fieldtrip to Lilstock about five years ago generated the excitement that led to our field campaign. We also thank Jan Engelder for her assistance in the field at Lilstock. Rob Knipe and David Sanderson are thanked for their role in the initial phases of our study. Comments by Bill Dunne, Kevin Smart and an anonymous reviewer greatly improving this paper. This work was funded by Penn State's Seal Evaluation Consortium (SEC).

\section{References}

Arthur, M.J., 1989. The Cenozoic evolution of the Lundy pull-apart basin into the Lundy rhomb horst. Geological Magazine 126, 187-198.

Balk, R., 1937. Structural Behavior of Igneous Rocks. Geological Society of America Memoir 5.

Beck, M.E., Rojas, C., Cembrano, J., 1993. On the nature of buttressing in margin-parallel strike-slip fault systems. Geology 21, 755-758.

Bergerat, F., 1987. Stress fields in the European platform at the time of Africa-Eurasia collision. Tectonics 6, 99-132.

Bevan, T.G., Hancock, P.L., 1986. A late Cenozoic regional mesofracture system in southern England and northern France. Journal of the Geological Society, London 143, 355-362.

Blair, B.E., 1955. Physical properties of mine rock, Part 3. U.S. Bureau of Mines Report of Investigations 5130, Washington D.C.

Blair, B.E., 1956. Physical properties of mine rock, Part 3. U.S. Bureau of Mines Report of Investigations 5244, Washington D.C.

Brereton, N.R., Evans, C.J., 1987. Rock stress orientations in the United Kingdom from borehole breakouts. Report of the Regional Geophysics Research Group, British Geological Survey, No. R6 87/14.

Cruikshank, K.M., Aydin, A., 1995. Unweaving the joints in Entrada Sandstone, Arches National Park, Utah, USA. Journal of Structural Geology 17, 409-421.

Dart, C.J., McClay, K., Hollings, 1995. 3D analysis of inverted extensional fault systems, southern Bristol Channel basin, UK. In: Buchanan, J.G., Buchanan, P.G. (Eds.), Basin Inversion. Geological Society Special Publication 88, pp. 393-413.

Dyer, R., 1988. Using joint interactions to estimate paleostress ratios. Journal of Structural Geology 10, 685-699.

Donath, F.A., Parker, R.B., 1964. Folds and folding. Bulletin of the Geological Society of America 75, 45-62.

Engelder, T., Fischer, M.P., 1996. Loading configurations and driving mechanisms for joints based on the Griffith energy-balance concept. Tectonophysics 256, 253-277.

Engelder, T., Geiser, P.A., 1980. On the use of regional joint sets as trajectories of paleostress fields during the development of the 
Appalachian Plateau, New York. Journal of Geophysical Research 85, 6319-6341.

Engelder, T., Lacazette, A., 1990. Natural hydraulic fracturing. In: Barton, N., Stephansson, O. (Eds.), Rock Joints. A.A. Balkema, Rotterdam, pp. 35-44.

Fischer, M.P., 1994. Application of Linear Elastic Fracture Mechanics to Some Problems of Fracture and Fault Propagation. Ph.D. Thesis, The Pennsylvania State University, University Park, PA.

Ghosh, S.K., 1993. Structural Geology: Fundamentals and Modern Developments. Pergamon Press, Oxford.

Gross, M.R., Fischer, M.P., Engelder, T., Greenfield, R.J., 1995. Factors controlling joint spacing in interbedded sedimentary rocks: Integrating numerical models with field observations from the Monterey Formation, USA. In: Ameen, M.S. (Ed.), Fractography: Fracture Topography as a Tool in Fracture Mechanics and Stress Analysis. Geological Society Special Publication 92, pp. 215-233.

Hamblin, W.K., 1965. Origin of "reverse drag" on the downthrow side of normal faults. Bulletin of the Geological Society of America 76, 11451164.

Hancock, P.L., 1969. Jointing in the Jurassic limestones of the Cotswold Hills. Proceedings of the Geological Association 80, 219-241.

Hancock, P.L., 1985. Brittle microtectonics: principles and practice. Journal of Structural Geology 7, 437-457.

Hancock, P.L., Engelder, T., 1989. Neotectonic Joints. Geological Society of America Bulletin 101, 1197-1208.

Hatheway, A.W., Kiersch, G.A., 1982. Engineering properties of rock. In: Carmichael, R.S. (Ed.), Handbook of Physical Properties or Rock, 1. CRC Press Inc, Boca Raton, Florida, pp. 289-311.

Hills, E.S., 1963. Elements of Structural Geology. John Wiley and Sons, New York.

Hobbs, D.W., 1967. The formation of tension joints in sedimentary rocks: an explanation. Geological Magazine 104, 550-556.

Hodgson, R.A., 1961. Regional study of jointing in Comb Ridge-Navajo mountain area, Arizona and Utah. American Association of Petroleum Geologists, Bulletin 45, 1-38.

Holloway, S., Chadwick, R.A., 1986. The Sticklepath-Lustleigh fault zone: Tertiary sinistral reactivation of a Variscan dextral strike-slip fault. Journal of the Geological Society of London 143, 452-477.

Hudleston, P.J., Treagus, S.H., Lan, L., 1996. Flexural flow folding: does it occur in nature? Geology 24, 203-206.

Kelly, P.G., Sanderson, D.J., Peacock, D.C.P., 1998. Linkage and evolution of conjugate strike-slip fault zones in limestones of Somerset and Northumbria. Journal of Structural Geology 20, 1477-1494.

LaPointe, P.R., Hudson, J.A., 1985. Characterization and interpretation of rock mass joint patterns, Geological Society of America Special Paper 199.

Loosveld, R.J.H., Franssen, R.C.M.W., 1992. Extensional vs. shear fractures: implications for reservoir characterization. Society of Petroleum Engineers 25017, 23-30.

Narr, W., Suppe, J., 1991. Joint spacing in sedimentary rocks. Journal of Structural Geology 13, 1037-1048.

Nemcok, M., Bayer, R., Miliorizos, M., 1995. Structural analysis of the inverted Bristol Channel Basin: implications for the geometry and timing of fracture porosity. In: Buchanan, J.G., Buchanan, P.G. (Eds.), Basin Inversion. Geological Society Special Publication 88, pp. 355-392.

Nickelsen, R.P., Hough, V.D., 1967. Jointing in the Appalachian Plateau of Pennsylvania. Geological Society of America Bulletin 78, 609-630.
Peacock, D.C.P., Sanderson, D.J., 1992. Effects of layering and anisotropy on fault geometry. Journal of the Geological Society, London 149, 793802.

Plumb, R.A., Evans, K.F., Engelder, T., 1991. Geophysical log responses and their correlation with the bed-to-bed stress contrasts in Paleozoic rocks of the Appalachian Plateau, New York. Journal of Geophysical Research 96, 14509-14528.

Pollard, D.D., Segall, P., 1987. Theoretical displacements and stresses near fractures in rock: with applications to faults, joints, veins, dikes, and pressure solution surfaces. In: Atkinson, B.K. (Ed.), Fracture Mechanics of Rock. Academic Press, London.

Price, N.J., Cosgrove, J.W., 1990. Analysis of Geological Structures. Cambridge University Press, Cambridge.

Priest, S.D., 1993. Discontinuity Analysis for Rock Engineering. Chapman and Hall, London.

Ramsay, J.G., 1962. The geometry and mechanics of formation of "similar" type folds. Journal of Geology 70, 309-327.

Ramsay, J.G., 1967. The Folding and Fracturing of Rocks. McGraw-Hill, New York.

Ramsay, J.G., Huber, M.I., 1987. The Techniques of Modern Structural Geology, 2: Folds and Fractures. Academic Press, Inc, Orlando.

Rawnsley, K.D., Rives, T., Petit, J.-P., Hencher, S.R., Lumsden, A.C., 1992. Joint development in perturbed stress fields near faults. Journal of Structural Geology 14, 939-951.

Rawnsley, K.D., Peacock, D.C.P., Rives, T., Petit, J.-P., 1998. Joints in the Mesozoic sediments around the Bristol Channel Basin. Journal of Structural Geology 20, 1641-1661.

Secor, D.T., 1965. Role of fluid pressure in jointing. American Journal of Science 263, 633-646.

Terzhagi, R.D., 1965. Sources of errors in joint surveys. Geotechnique 15, 287-304.

Van Hise, C.R., 1896. Principles of North American Pre-Cambrian geology, U.S. Geological Survey 16th Annual Report, 581-874.

Wawrzynek, P.A., Ingraffea, A.R., 1987. Interactive finite element analysis of fracture processes: an integrated approach. Theoretical and Applied Fracture Mechanics 8, 137-150.

Whittaker, A., Green, G.W., 1983. Geology of the Country around Westonsuper-Mare. Memoir of the Geological Survey of Great Britain, Sheet 279 and parts of 263 and 295.

Whitten, E.H.T., 1966. Structural Geology of Folded Rocks. RandMcNally, Chicago.

Wise, D.U., McCrory, T.A., 1982. A new method of fracture analysis; azimuth versus traverse distance plots. Geological Society of America Bulletin 93, 889-897.

Younes, A., Engelder, T., 1999. Fringe cracks: key structures for the interpretation of progressive Alleghanian deformation of the Appalachian Plateau. Geological Society of America Bulletin 111, 219-239.

Zhao, M., Jacobi, R.D., 1997. Formation of regional cross-fold joints in the northern Appalachian Plateau. Journal of Structural Geology 19, $817-$ 834

Zoback, M.D., Healy, J.H., 1984. Friction, faulting, and in situ stress. Annales Geophysicae 2, 689-698.

Zoback, M.L., 1992. First and second order patterns of stress in the lithosphere: The World Stress Map Project. In: Zoback, M.L. (Ed.), The World Stress Map Project. Journal of Geophysical Research 97, pp. 11703-11728. 